\title{
5 Inoffizielle Narrative zur Kampagne gegen Rechtsabweichler (mit offizieller Duldung)
}

Kurz nach dem Tode Mao Zedongs begannen nicht nur seine politischen Erben mit einem Ringen um die Zukunft Chinas und damit einhergehend mit einer politisch angemessenen Einordnung der eigenen Vergangenheit, auch zivilgesellschaftliche Akteure machten sich zunehmend Gedanken darüber, wie man die historischen Ereignisse der Mao-Zeit und die eigenen Erlebnisse in jenen Jahren bewerten und aufarbeiten könnte. Dabei ist langsam eine inoffizielle Geschichtsschreibung entstanden, die sich vorwiegend als Bottom-up-Prozess verstehen lässt und welche über die offiziellen Narrative der KPCh hinausgeht. Die Akteure dieser Art von Geschichtsschreibung agierten mit den von ihnen geschaffenen Narrativen zu den „historischen Fehlern“ der KPCh teilweise innerhalb und teilweise außerhalb der von der Partei vorgegebenen und nicht immer klaren Grenzen des Sagbaren, welche sich seitdem im Wesentlichen entlang der Herrschaftslegitimation der KPCh bewegen. Die Grenzen dieser staatlichen Toleranz haben sich seit den frühen 1980er Jahren - je nach aktueller politischer Lage - immer wieder verschoben. Den Untersuchungsgegenstand dieses Kapitels stellen Narrative dar, die sich diesseits jener politischen Grenzen des Sagbaren bewegen und deshalb von der Partei toleriert werden bzw. wurden.

Diese Tolerierung soll hier als aktiver Prozess verstanden werden, das heißt, er umfasst Veröffentlichungen, die staatlich legitimiert sind wie Bücher, die in einem staatlichen Verlag oder Geschichtszeitungen, die mit einer offiziellen Publikationslizenz regulär innerhalb Chinas veröffentlicht und auf dem freien Markt vertrieben werden konnten. Voraussetzung hierfür ist in der Regel eine Überprüfung der Inhalte durch die zuständige Behörde. ${ }^{390}$ Mit der Genehmigung lässt die KPCh durch die entsprechenden Entscheidungsträger in den Behörden also einen über den offiziellen Kanon hinausgehenden öffentlichen Diskurs über die Geschichte zu, ohne ihn selbst nach außen hin sichtbar führen zu müssen, also ohne ein Bild der Uneinigkeit zu vermitteln.

390 Alle Bücher, die in einem der offiziellen Buchverlage in China veröffentlicht werden sollen, mussten bis zum Jahr 2018 durch das Staatliche Hauptamt für Presse, Publikation, Radio, Film und Fernsehen (Zhonghua renmin gongheguo guojia xinwen chuban guangdian zongju 中华人民共和 国国家新闻出版广电总局) inhaltlich überprüft werden, um die Genehmigung zur Publikation zu erhalten. Seitdem ist die Propagandaabteilung des ZK der KPCh (Zhongguo gongchandang zhongyang weiyuanhui xuanchuan bu 中国共产党中央委员会宣传部) direkt für die Überprüfung der Inhalte zuständig. Zum Thema Zensur in China siehe Roberts 2018.

Ә OpenAccess. (C) 2021 Anja Blanke, publiziert von De Gruyter. (cc) BY-NC-ND Dieses Werk ist lizenziert unter der Creative Commons Attribution-NonCommercial-NoDerivatives 4.0 International Lizenz. 
Im Gegensatz zu den Akteuren der offiziellen Geschichtsschreibung zur Kampagne gegen Rechtsabweichler, sind die Akteure dieser Kategorie sehr vielschichtig; es waren vorwiegend Zeitzeugen bzw. die Opfer der Kampagne und ihre Angehörigen, Vertreter der nach dem Tode Maos in die Städte zurückgekehrten Rotgardisten, teilweise aber auch Mitglieder der KPCh und in einigen Fällen Historiker, die sich an der Entstehung dieser alternativen Betrachtung der Vergangenheit beteiligten. Daraus entstanden sehr unterschiedliche Textarten und vielschichtige Narrative, wie im Folgenden genauer dargelegt wird. Die einen verbinden die alternative Geschichtsschreibung mit (versteckten) politischen Forderungen, andere hingegen dienen der Verarbeitung des eigenen Traumas der Opfer, und manche Textarten verbinden diese beiden Aspekte miteinander. Einen besonderen Stellenwert nehmen dabei jedoch die persönlichen Erinnerungen von Zeitzeugen ein. Trotz der Vielschichtigkeit der Betrachtung der Vergangenheit dieser Kategorie, hat der Großteil der Texte eines gemeinsam: Sie fordern die offizielle Geschichtsschreibung der KPCh heraus, in der Regel stellen sie deren Herrschaftslegitimation im Zuge dessen jedoch nicht grundsätzlich in Frage.

Dieses Kapitel beleuchtet dabei auch die historischen Hintergründe der Entstehung und Entwicklung der inoffiziellen Narrative der Kampagne gegen Rechtsabweichler. Gezeigt werden soll insbesondere, dass im Laufe der Jahre ein Spannungsfeld zwischen offizieller und inoffizieller Geschichtsschreibung entstanden ist, welches bei den hier untersuchten Narrativen zum einen auf einer Neudeutung der Geschichte, die über das offizielle Narrativ hinausgeht, beruht und zum anderen jedoch auch darauf, dass diese Narrative häufig mit politischen Botschaften verknüpft worden sind. Dieses Spannungsfeld stellt zudem einen Erklärungsansatz für die Zuspitzung des Kampfes um das kollektive Gedächtnis dar.

\subsection{Die Entstehung und Entwicklung inoffizieller Narrative innerhalb der VR China}

Im April 1976, also bereits rund fünf Monate vor dem Tode Maos, wurde erstmals das Tabu gebrochen, den sakrosankten Führer öffentlich zu kritisieren. Während des Qingming-Festes, bei dem traditionell der Toten gedacht wird, kam es zu einem spontanen Massenauflauf auf dem Platz des Himmlischen Friedens. Einfache Bürger, die zunächst dem kürzlich verstorbenen und im Volk sehr beliebten Zhou Enlai Respekt zollen wollten, gingen nach und nach zu einem öffentlichen Wehklagen über die Gewalt und Ungerechtigkeit der Kulturrevolution über. Dabei wurde Mao zwar nicht direkt, jedoch aber indirekt durch das Vortragen von entsprechenden Gedichten angeprangert. Zudem formulierten einige Bürger vor- 
sichtig ihren Wunsch nach politischen Veränderungen. Dabei ging es ihnen allerdings noch nicht darum, die Partei in Frage zu stellen, vielmehr wünschten sie sich eine Rückkehr in die goldenen 1950er Jahre, als der Parteiapparat noch die Kontrolle innehatte. ${ }^{391}$ Der Blick der Bürger, die sich im Zuge dessen äußerten, auf die 1950er Jahre dürfte auch deshalb so positiv ausgefallen sein, da die meisten sogenannten Rechtsabweichler sich zu dem Zeitpunkt noch im Laogai-System befanden und sie noch nicht Teil des aktiven Diskurses gewesen sind. Auch wenn die Ereignisse im April 1976 noch keine offene Revolte oder Demokratiebewegung darstellten, deutete sich dennoch an, dass in der Gesellschaft etwas in Bewegung kommen könnte, auch hinsichtlich der Bewertung der eigenen Vergangenheit und der darin begangenen Fehler der KPCh.

\section{Die Phase der intellektuellen Neuorientierung}

Bereits kurz nach Maos Tod meldeten sich dann auch Intellektuelle zu Wort, die seine Fehler öffentlich kritisierten. ${ }^{392}$ In der Zeit des politischen Umbruchs spielte die Rotgardistengeneration durchaus eine wichtige Rolle im Ringen um die Zukunft Chinas. Ab dem Jahr 1976 kehrten die während der Kulturrevolution aufs Land verschickten Jugendlichen mit Schulbildung (zhishi qingnian 知识青年) nach und nach in die Städte zurück. ${ }^{393}$ Die meisten von ihnen fügten sich zwar schnell wieder in das System ein, setzten ihre unterbrochene Schulbildung fort oder besuchten eine Universität, dennoch begannen einige, angetrieben von ihrer durch die Kulturrevolution ausgelösten Desillusion, die Partei in Frage zu stellen bzw. sich für den politischen Umbruch zu engagieren. Im November 1978 brachten diese Aktivisten an einer Mauer in der Xidan-Straße in Peking Wandzeitungen ${ }^{394}$ an, auf denen sie erste politische Forderungen sowie ihre Kritik an Mao zum Ausdruck brachten. Die dadurch initiierte Demokratiemauerbewegung (minzhu qiang yundong 民主墙运动) kann als die erste Massenbewegung im postmaoistischen China angesehen werden. Neben Studenten und Intellektuellen schlossen

391 Goldman 2005, S. $27 \mathrm{f}$.

392 Ebd., S. 51.

393 Einige dieser Jugendlichen sind im Laufe der Kulturrevolution auch freiwillig zur Arbeit aufs Land gegangen, um ihren revolutionären Geist zu demonstrieren. Die meisten wurden jedoch im Zuge des Versuchs der Partei, die wütenden Roten Garden unter Kontrolle zu bringen und die politische und gesellschaftliche Ordnung wiederherzustellen, ab dem Jahr 1968 aufs Land verschickt. Siehe Walder 2009.

394 Wandzeitungen (dazibao 大字报) waren während der Kulturrevolution ein sehr häufig verwendetes Medium der politischen Willensbildung und der Mobilisierung der Massen. Siehe Benton und Hunter 1995, S. 104 ff. 
sich dieser Bewegung, die zunehmend auch mit großen Demonstrationen einherging, nach und nach auch Arbeiter an. ${ }^{395}$ Das von den Aktivisten formulierte und über Flugblätter und Poster verbreitete politische Ziel war im Wesentlichen die Einrichtung rationaler bürokratischer Institutionen als Garantie für sozialistische Demokratie und zur Ausrottung der bürokratischen Klasse. Die Demokratie sahen viele von ihnen dabei als Weg, die Konflikte zwischen der herrschenden Bürokratie und dem Volk zu beenden. Die Aktivisten bedienten sich für die Formulierung ihrer Forderungen meist der ihnen bekannten und während der Kulturrevolution erlernten, marxistischen Terminologie. Sie bezogen sich dabei jedoch eher auf klassische marxistische Argumente und kehrten damit an die Quelle des Marxismus zurück. Demnach seien beispielsweise Wahlen ein Instrument zur Überwachung der Partei, welches die moralische und ideologische Reinheit des Beamtentums sicherstellen solle. ${ }^{396}$ Es gab jedoch auch eine andere Gruppe von Aktivisten, die einen eklektischen Ansatz für ihre Suche nach politischen Ideen und demokratischen Institutionen nutzte. Ihre Forderungen nach westlichen demokratischen Konzepten und Ideen wie Meinungs- und Pressefreiheit oder Menschenrechten versuchten sie ebenfalls mit marxistischen Erklärungsansätzen zu rechtfertigen. Diese Gruppe der Aktivisten interessierte sich jedoch eher für die Formen, weniger für die konkreten Inhalte westlicher Demokratien. $\mathrm{Zu}$ berücksichtigen gilt hier, dass ihnen aufgrund ihrer ideologischen Bildung während der Kulturrevolution konkrete westliche demokratische Konzepte zu diesem Zeitpunkt noch weitgehend unbekannt gewesen sind. Nur eine Minderheit der Intellektuellen richtete sich zu diesem Zeitpunkt aktiv gegen den Marxismus. ${ }^{397}$ Viele Intellektuelle des Establishments sind während der Bewegung jedoch stumm geblieben, auch wenn sie vielleicht Sympathien für die Forderungen der Bewegung hegten, denn ihren neu erworbenen Status wollten sie nicht gleich wieder verlieren. ${ }^{398}$ Ein weiterer Grund für die Passivität einiger Intellektueller in dieser Bewegung kann auch darin zu finden sein, dass sie nach dem Ende des „Roten Zeitalters“ 1976 einfach nur Erleichterung darüber verspürten, als intellektuelle Klasse scheinbar nicht mehr Gefahr zu laufen, Gegenstand politischer Verfolgung zu werden, und dieses neue Lebensgefühl möglicherweise nicht gleich wieder verlieren wollten.

Und dennoch hatte die Rotgardistengeneration auch einige Aktivisten hervorgebracht, die sich jetzt nicht mehr der Partei, sondern der Nation als Ganzem

395 Goldman 2005, S. 30 f.

396 Paltemaa 2007, S. 610 ff.

397 Ebd., S. 620.

398 Goldman 2005, S. 50. 
verpflichtet fühlten und recht unabhängig agierten. Wie Lauri Paltemaa ausführt, berichtete später eine Reihe jener Rotgardisten, die sich an der Demokratiemauerbewegung beteiligten, dass sie die Kulturrevolution als Zeit des Erwachens ihres politischen Bewusstseins erlebt hätten. ${ }^{399}$ Deng Xiaoping ließ die meist jungen Aktivisten zunächst gewähren. Die Bewegung diente zu Beginn durchaus auch seinen eigenen politischen Zielen, denn auch er suchte die politische Erneuerung. Außerdem verstand er es geschickt, die Demonstrationen gegen seine Gegner innerhalb der Partei einzusetzen. In der Zeit entstanden auch einige inoffizielle Magazine, wie Fruchtbare Erde (wotu 沃土), Pekinger Frühling (Beijing zhichun 北 京之春) oder das Journal für Menschenrechte (renquan bao 人权报), welche in ihren Beiträgen neben Forderungen nach tiefgreifenden politischen Veränderungen auch Kritik an Mao hervorbrachten. Auch die Beiträge dieser Zeitschriften bewegten sich zu jener Zeit für einige Monate innerhalb der staatlichen Toleranzgrenze. Letztlich gingen Deng Xiaoping die Forderungen der Aktivisten jedoch $\mathrm{zu}$ weit, stellten sie durch ihre Suche nach neuen Institutionen und Ideen letztlich doch eine Herausforderung der Alleinherrschaft der KPCh dar. Am 30. März 1979 äußerte er im Zuge der Theoriekonferenz der KPCh erstmals öffentlich Kritik an der Bewegung und ihren Anhängern. Dabei regte er an, dass die ideologische Verwirrung der Jugend bereinigt werden müsste. Eigentlich hatte er die Bewegung bereits seit dem 3. Plenum des 11. Zentralkomitees, welches im Zeitraum vom 12. bis 22. Dezember 1978 abgehalten worden war und aus dem er als Führer Chinas hervorgegangen ist, schon nicht mehr für seine Zwecke benötigt. Und so begann er die Bewegung ab der zweiten Jahreshälfte 1979 allmählich zu unterdrücken. ${ }^{400}$ Viele der im Jahr zuvor gegründeten inoffiziellen Journale wurden im Zuge dessen verboten, so auch das Magazin Pekinger Frühling, das seit November 1979 offiziell seine Verbreitung einstellen musste. ${ }^{401}$

Die Entwicklung des politischen Bewusstseins der ehemaligen Rotgardisten erklärt, warum sie zu politischen Aktivisten des frühen post-maoistischen China geworden sind. Dies dient zudem auch als Erklärungsansatz, warum sich einige von ihnen, neben Opfern der Kampagnen und teilweise (ehemals) hochrangigen

\footnotetext{
399 Paltemaa 2007, S. 611.

400 Goldman 2005, S. $45 \mathrm{ff}$.

401 Das Magazin Pekinger Frühling operierte danach einige Zeit im Untergrund und wurde über geheime Kanäle verbreitet. Im Juni 1993 wurde es im Ausland neu gegründet. Neben der Förderung von Menschenrechten in China beteiligt es sich auch an einer inoffiziellen Geschichtsschreibung zu den „historischen Fehlern“ der KPCh. Siehe Beijing Spring 北京之春 2004, http:// beijingspring.com/en/.

Somit gehört das Journal seit November 1979 zum Bereich der inoffiziellen Geschichtsschreibung, der durch die Partei nicht mehr toleriert wird.
} 
Parteikadern, im Laufe der kommenden Jahre aktiv an einer Neudeutung der Geschichte jenseits offizieller Narrative beteiligen würden. Und obwohl die Demokratiemauerbewegung im Dezember 1979 letztlich niedergeschlagen wurde, nutzten in der Zeit des politischen Umbruchs nach dem Tode Maos jene liberalen Kräfte und Intellektuelle die Gunst der Stunde und entwickelten und verbreiteten bedeutende alternative ideologische und politische Konzepte - allen voran der damalige Philosophieabsolvent der Peking-Universität Hu Ping 胡本, der im Jahr 1979 unter dem Pseudonym He Bian 河边 (wörtl.: am Flussufer) das Essay Zur Redefreiheit (lun yanlun ziyou 论言论自由) veröffentlichte. Er sollte später noch eine wichtige Rolle für die Neudeutung der Kampagne gegen Rechtsabweichler spielen. ${ }^{402}$

In diesem politischen Pamphlet setzt er sich für eine Überwindung des Totalitarismus und die Errichtung einer Demokratie in China ein. Als wichtigstes Instrument auf diesem Weg sieht er die Redefreiheit an und so betont er zugleich, dass ohne sie auch keine echte Demokratie möglich sei. Als erster Schritt auf dem Weg zur Überwindung des Totalitarismus sei es jedoch zunächst notwendig, in der Bevölkerung ein Bewusstsein für die Redefreiheit zu schaffen, da die meisten Menschen in Ländern, in denen es keine Redefreiheit gibt, auch kein Bewusstsein dafür hätten. Die Förderung der Redefreiheit müsse demnach dadurch erreicht werden, dass die Menschen sie verstehen und beherrschen. ${ }^{403}$

Im Zuge seiner Forderung nach Redefreiheit argumentiert er, dem Geist der Mehrheit der Aktivisten der Demokratiemauerbewegung entsprechend, nicht gegen, sondern im Einklang mit dem Marxismus, wonach sie essentiell für das Schaffen eines „echten“ Marxisten sei:

\footnotetext{
Wir wollen echte Marxisten erschaffen, genau dafür bedarf es einer echten Redefreiheit. Die Menschen können nur dann an die Wahrheit glauben, wenn sie unterschiedliche Meinungen vollständig verstanden haben. Die Menschen können die Theorie nur dann wirklich beherrschen, wenn sie in einer gleichberechtigten Debatte, die auch falsche Ideen einschließt, obsiegen können. Es ist schwierig, Willkür, Vereinfachung und starke Worte zu vermeiden, wenn die andere Partei ihrer Stimme beraubt wird. Dies untergräbt nicht nur den Fortbestand der Wahrheit, sondern es untergräbt auch die Kritik an der Täuschung. Vor allem wird es aber die intellektuelle Kraft der Menschen untergraben und die guten Absichten der Menschheit auf der Suche nach der Wahrheit ruinieren. Es ist nicht so schrecklich, die
}

402 Die erste Fassung des Textes schrieb Hu Ping bereits im Jahr 1975, also noch unter dem direkten Eindruck der Kulturrevolution. Die vierte Fassung wurde schließlich im Februar 1979 im Untergrundmagazin Fruchtbare Erde veröffentlicht. Eine überarbeitete, fünfte Fassung wurde im November 1980 als Flugblatt auf dem Campus der Peking-Universität verteilt. Im Zuge dessen wurden Teile des Textes auf Poster gedruckt und auf dem Campus aufgehängt. Hu 1986, S. 1. 403 Ebd., S. 2. 
Wahrheit zu verlieren, aber es ist schrecklich, die Fähigkeit zu verlieren, die Wahrheit zu erreichen. [...] Die Schlussfolgerung ist sehr klar: Wenn wir keine wahre Redefreiheit praktizieren und keine Kritik an der marxistischen Wahrheit zulassen, können wir keine echten Marxisten erschaffen. ${ }^{404}$

In dem Essay gehen seine Forderungen nach Demokratie nicht etwa mit einem Aufruf zum Sturz der politischen Erben Maos respektive der KPCh einher, vielmehr möchte er eine Veränderung der politischen Verhältnisse durch die Förderung von Demokratie und Menschenrechten, Rede- und Meinungsfreiheit herbeiführen. Nicht der radikale Sturz des Regimes, sondern die Stärkung entsprechender Institutionen, die das Recht der freien Meinungsäußerung als erstes Recht der Bürger auch durchsetzen können, sollten die von ihm geforderten politischen Veränderungen ermöglichen.

In dem Essay verknüpft er sein Plädoyer für die Durchsetzung der Redefreiheit mit von der KPCh nach dem Tode Maos angestoßenen politischen Programmen, die die Modernisierung Chinas vorantreiben sollten. Dabei argumentiert er beispielsweise, dass die Redefreiheit ein wichtiger Bestandteil für eine erfolgreiche Umsetzung der Vier Modernisierungen darstelle:

Die Redefreiheit ist wie Luft: Nur wenn die Menschen sie verlieren, wird der Durchschnittsmensch ihren Existenzwert spüren. Der Schaden, der durch einen Mangel an Redefreiheit verursacht wird, ist wie ein Erstickungstod und die offenen Wunden sind nicht sichtbar. Das chinesische Volk leidet unter dem Mangel an Redefreiheit, ihrem Verlust und der Tiefe ihrer Nachwirkungen, die in der Welt selten sind. Heute müssen wir große Anstrengungen unternehmen, um uns dieser Geisteshaltung zu entledigen. Die Meinungsfreiheit ist eine grundlegende Aufgabe, deren Erreichen wir fördern müssen. Nur durch das gründliche Üben der Redefreiheit können wir den nationalen Geist der Offenheit und Integrität wiederherstellen. Ohne einen gesunden Geisteszustand können die „Vier Modernisierungen“ nicht erreicht werden. ${ }^{405}$

Auch wenn er nicht den Sturz der KPCh fordert, ruft er in seinem Essay doch zu einem anderen Umgang mit ihr durch das Volk auf, insbesondere dann, wenn die Mächtigen ihre Macht missbrauchen. Er fordert den Mut des Fortschritts ein. Das heißt, mit dem Mittel der Redefreiheit wäre es demnach möglich, Machtmissbrauch einzuschränken und unter Umständen sogar ganz zu unterbinden. Strukturelle Veränderungen fordert er jedoch auch, indem er darlegt, dass es für

404 Eigene Übersetzung. Original siehe ebd., S. 13f.

405 Eigene Übersetzung. Original siehe ebd., S. 20. 
eine erfolgreiche Zukunft Chinas notwendig sei, dass die Machtbefugnisse der Führer Chinas eingeschränkt würden. ${ }^{406}$

Zur Redefreiheit ist in einer ersten Fassung noch unter dem unmittelbaren Eindruck der Kulturrevolution entstanden, dennoch vermeidet $\mathrm{Hu}$ in dem Essay eine direkte Kritik an Mao Zedong. Er macht ihn sich sogar für sein Plädoyer für die Redefreiheit zunutze. Er merkt dabei an: „Der Genosse Mao Zedong hat viele korrekte Ausführungen zum Thema Meinungsfreiheit getätigt. “407 Hus Kritik an den Fehlern der Vergangenheit stellt sich eher abstrakt dar und richtet sich nur implizit auch an die KPCh. Dennoch betont er, dass schwere Fehler, die nach der Gründung der VR China gemacht worden seien, keinesfalls wiederholt werden dürften:

Wenn wir auf die Vergangenheit zurückblicken, haben wir bei einigen wichtigen Themen falsche Entscheidungen getroffen, deren Ergebnisse teilweise katastrophal waren. Diese sogenannte Katastrophe liegt nicht nur darin, dass die mit der Zeit durch falsche Entscheidungen verursachten Verluste immer schwerwiegender wurden, sondern auch in der selbstgewählten, falschen Struktur, die mit der Zeit immer stärker geworden ist. In anderen Worten, die falschen Entscheidungen waren so eigenartiger Natur, dass es, je schwerwiegender die Fehler gewesen sind, auch immer schwieriger geworden ist, ihre Ursache zu korrigieren. Im Ergebnis wurde immer so lange gewartet, bis der Fehler gemacht worden ist. Die Geschichte ist manchmal eine enge Gasse, in der man nicht umkehren kann. Man kann fehlgeleitet werden, wenn man eine Entscheidung zu Beginn getroffen hat, und dann hat man fast keine Chance mehr, den Weg zu korrigieren. Man kann ihn dann nur bis zum Ende gehen, bevor man einen neuen einschlagen kann. Zum Beispiel offenbarte sich die Katastrophe, die vor drei Jahren endete, bereits vor 23 Jahren, als die Bemühungen vieler Menschen umzudrehen fehlschlugen. Deshalb wollen wir hier zwei Lektionen zusammenfassen: Erstens müssen wir unser Bestes geben, in dem Moment der Entscheidung gründlich nachzudenken, und zweitens sollten wir danach streben, nach der Entscheidung noch einen Raum für Veränderung zu haben. Ich befürchte, dass uns die Geschichte nicht noch einmal die Möglichkeit geben wird, einen solchen katastrophalen Fehler zu machen. ${ }^{408}$

Konkrete „historische Fehler“ wie die Kampagne gegen Rechtsabweichler und insbesondere die Kulturrevolution werden zwar wiederholt vage angesprochen, jedoch findet in diesem Text noch keine konkrete kritische Auseinandersetzung mit diesen Ereignissen statt. Hu Ping macht durch das vage Ansprechen dieser Ereignisse jedoch deutlich, dass die Redefreiheit ein Mittel darstellen kann, solche Fehler in Zukunft zu vermeiden. Im Zusammenhang eines kritischen Diskurses um die Vergangenheit, lassen sich wiederholt kritische Aussagen Hus zur

406 Ebd., S. 29. Vgl. Müller 1997, S. $231 \mathrm{ff}$.

407 Eigene Übersetzung. Original siehe Hu 1986, S. 7.

408 Eigene Übersetzung. Original siehe ebd., S. 31. 
Viererbande erkennen. In dieser Hinsicht begibt er sich ebenfalls nicht in eine direkte oppositionelle Haltung zur KPCh, sondern agiert gewissermaßen sogar im Sinne der Partei, die die Viererbande nach ihrer Verhaftung als Hauptschuldige für das Ausufern der Kulturrevolution öffentlich an den Pranger stellen sollte. Auch hier unterstreicht er seine Forderung nach Überwindung des Totalitarismus, indem er erneut einen Bezug zur Modernisierung Chinas herstellt:

Es ist wahr, dass unter der feudalen Autokratie der „Viererbande“ eine Modernisierung absolut unmöglich ist. Dennoch muss angemerkt werden, dass der Autoritarismus des „Viererbanden“-Modells nicht nur die extremste Art des Autoritarismus darstellt, sondern sich auch die rauesten und niedersten Energien zunutze macht. Die Geschichte zeigt uns, dass es noch immer Formen des Autoritarismus gibt, die weniger extrem und effizient sind, ebenso wie es autoritäre Systeme gibt, die zwar ebenso extrem, aber noch effizienter sind. ${ }^{409}$

$\mathrm{Hu}$ Pings Auseinandersetzung mit dem Thema Redefreiheit stellt somit einen wichtigen Bezug zur Aufarbeitung von „historischen Fehlern“ durch eine inoffizielle Geschichtsschreibung her, denn eine über die offizielle Geschichtsschreibung hinausgehende alternative Betrachtung der Geschichte stellt auch einen Akt der Ausübung der Redefreiheit dar.

Diese Phase des politischen Umbruchs brachte eine Reihe von unabhängigen Intellektuellen hervor, die sich später, ähnlich wie Hu Ping, auch aktiv an einer alternativen Geschichtsschreibung beteiligen sollten. Dabei sollte diese Form der Betrachtung der Vergangenheit Chinas zunehmend auch mit Forderungen nach politischen Veränderungen einhergehen. Trotz des Scheiterns der Demokratiemauerbewegung, ließ es das politische Klima Ende der 1970er Jahre zu, dass kritische Debatten über die Mao-Zeit sogar in offiziellen Presseorganen wie der Renmin Ribao geführt werden konnten. ${ }^{410}$ Dies dürfte auch deshalb möglich gewesen sein, weil die KPCh in dieser Phase noch selbst um eine angemessene Bewertung ihrer Vergangenheit und der von ihr selbst begangenen „historischen Fehler“ rang, welche erst 1981 mit der Veröffentlichung der Resolution einen festen offiziellen Rahmen bekommen würde.

Eine wichtige Rolle in dieser Frühphase der inoffiziellen Geschichtsschreibung zur Kampagne gegen Rechtsabweichler spielten insbesondere die Opfer der Kampagne, welche auch einen wichtigen Stellenwert im Kampf um das kollektive Gedächtnis einnahmen. Erste konkrete inoffizielle Betrachtungen der Ereignisse der Jahre 1957 und 1958 sowie eine Aufarbeitung des Leids der Opfer im LaogaiSystem, wurden mit der sogenannten Mauerliteratur (daqiang wenxue 大墙文学)

409 Eigene Übersetzung. Original siehe ebd., S. 31.

410 Béja 2019, S. 23. 
veröffentlicht, ein Genre, das durch Cong Weixi 从维 begründet worden ist. Der Journalist und Schriftsteller war im Jahr 1957 selbst zum Rechtsabweichler verurteilt worden und verblieb bis zum Jahr 1979 in verschiedenen Lagern des LaogaiSystems. Unter dem Eindruck seiner traumatischen Erlebnisse in den Lagern veröffentlichte er noch im Jahr der Korrektur seines Urteils und der Rückkehr in die Gesellschaft die Erzählung Eine Rote Magnolie am Fuße der Mauer (Daqiang xia de hong yulan 大墙下的红玉兰). In dieser verarbeitete er sein persönliches Trauma, das durch seine 22-jährige Gefangenschaft, die schlechten Haftbedingungen und die Demütigungen innerhalb des Lagersystems ausgelöst worden war. In den kommenden Jahren veröffentlichte er noch eine Reihe weiterer Erzählungen und Romane, die auf seinem individuellen Gedächtnis bzw. seinen persönlichen Erlebnissen und Eindrücken ab dem Jahr 1957 beruhten. ${ }^{411}$

In der Regel wurden solche Veröffentlichungen in den späten 1970er Jahren und den 1980er Jahren durch die KPCh toleriert, da ihr Fokus eher auf der Aufarbeitung der persönlichen Erfahrungen der Autoren lag und sie meistens auch keine strukturelle Kritik an der KPCh aufwiesen und ihre Herrschaftslegitimation nicht direkt herausforderten. Und so konnten Erzählungen, Romane und Memoiren dieser Art auf legalem und staatlich legitimiertem Wege veröffentlicht und vertrieben werden. Anders ausgedrückt bewegten sich die Autoren solcher Texte in jenen Jahren mehrheitlich innerhalb der von der Partei bestimmten Grenzen des Sagbaren. Insgesamt agierten die Intellektuellen während der 1980er Jahre zunehmend furchtloser, denn erstmals seit knapp drei Jahrzehnten wurden sie nicht mehr zur Zielscheibe großer Kampagnen. Wenn sie in dieser Zeit dennoch einmal außerhalb der Grenzen des von der Partei Tolerierbaren agierten, wurden nur kleinere, gezielte Maßnahmen ergriffen, die das Klima der Liberalisierung jener Jahre insgesamt nicht nennenswert einschränkten. ${ }^{412}$

Das kollektive Gedächtnis und die inoffizielle Geschichtsschreibung wurden in den 1980er Jahren also in erster Linie durch diejenigen geprägt, die die „historischen Fehler“ der KPCh am eigenen Leibe zu spüren bekommen hatten. Das kollektive Gedächtnis wird durch diese Akteure auch deshalb so stark geprägt, weil es Intellektuelle gewesen sind, die der Kampagne gegen Rechtsabweichler zum Opfer gefallen waren - eine Personengruppe, die eine entsprechende Ausbildung und die intellektuellen Fähigkeiten besaß, ihre Erlebnisse in unterschiedlicher Form schriftlich festzuhalten und zu verbreiten. Wären der Kampagne gegen Rechtsabweichler vorwiegend Arbeiter und Bauern zum Opfer gefallen, wäre das kollektive Gedächtnis möglicherweise nicht so sehr durch das Opfer-

411 Müller 2004a, S. 61f.

412 Goldman 1996, S. 37. 
narrativ, sondern stärker durch andere Akteure der Geschichtsschreibung geprägt worden. Die akademische Geschichtsschreibung zur Kampagne gegen Rechtsabweichler hat während der 1980er Jahre im Kampf um das kollektive Gedächtnis allerdings nur eine untergeordnete Rolle gespielt. Auch wenn an Hochschulen, so wie im gesamten Land, in jenen Jahren sehr große intellektuelle Freiheiten herrschten und sich Geisteswissenschaftler zunehmend mit westlichen Ideen und Konzepten beschäftigten, die aufgrund der Öffnung Chinas ins Land strömten, spielte die jüngere chinesische Parteigeschichte nach 1949 in den staatlichen Hochschulen in dieser Dekade kaum eine Rolle. Insbesondere befassten sich die durch den Staat ausgebildeten Historiker noch kaum mit den „historischen Fehlern“ der Partei. ${ }^{413}$ Diese Entwicklung führte dazu, dass in dieser Phase kaum alternative Narrative zum Kampf gegen die Rechten auf Makroebene entstanden sind, und so schien es zunächst, als sei das von der KPCh festgelegte Narrativ zur Kampagne gegen Rechtsabweichler nicht ernsthaft in Gefahr.

Nur wenige Jahre nach den politischen Umbrüchen nach dem Tode Maos sollte sich jedoch andeuten, dass sich das offizielle Narrativ der Geschichte der KPCh, welches 1981 durch die Resolution festgelegt worden war, nicht nachhaltig als dominierendes Narrativ des kollektiven Gedächtnisses in China durchsetzen konnte. Dies lag nicht nur an den großen intellektuellen Freiheiten der 1980er Jahre, sondern auch daran, dass die Festigung des offiziellen Narrativs in der ideologischen Ausbildung der Jugendlichen in den 1980er Jahren nur eine untergeordnete Rolle spielte.

Das politische Klima und der Umgang mit den Intellektuellen änderte sich nach den Studierendenprotesten 1989 rapide, sah sich die KPCh doch nun mit der Situation konfrontiert, um ihre Herrschaftslegitimation kämpfen zu müssen. Die dadurch stark zunehmende staatliche Zensur hatte auch einen großen Einfluss auf die staatliche Toleranz von Veröffentlichungen, die sich mit „historischen Fehlern“ der KPCh beschäftigten. Da die Studierendenproteste im Jahr 1989 die Legitimitätskrise der Partei offen zu Tage treten ließ, konnten einige Veröffentlichungen zu „historischen Fehlern“ der Partei, die im gleichen Stil von den Behörden zuvor toleriert worden waren, nicht mehr innerhalb Chinas veröffentlicht werden. Bezogen auf die Kampagne gegen Rechtsabweichler durfte beispielsweise der im Jahr der Studierendenproteste erschienene Roman Gewohnt zu sterben (Xiguan siwang 习惯死亡) von Zhang Xianliang 张贤亮 in China zunächst nicht veröffentlicht werden und war nur auf dem Schwarzmarkt erhältlich. Das Buch thematisiert die Auswirkungen des Traumas der verurteilten Intellektuellen nach ihrer Rückkehr aus dem Laogai-System in die Gesellschaft. Der Schriftsteller,

413 Siehe Yang und Liu 2016. 
der im Jahr 1957 ebenfalls als Rechtsabweichler verurteilt worden war und fast 22 Jahre unter den Schrecken der Umerziehungslager leiden musste, hatte in den Jahren zuvor bereits ganz ähnliche Schriften in China veröffentlicht, die sich mit dem Schicksal der Intellektuellen nach der Kampagne gegen Rechtsabweichler und während der Kulturrevolution beschäftigten, wie beispielsweise der im Jahr 1984 erschienene Roman Die Pionierbäume (Lühua shu 绿化树). ${ }^{414}$ Insgesamt wurde die intellektuelle Gemeinschaft in China nach den Ereignissen des Jahres 1989 zunächst zurück in die Passivität gedrängt.

\section{Erinnerungsboom ab den 1990er Jahren}

Trotz dieses vorübergehenden Zurückdrängens der Intellektuellen in die Passivität gelang es der Partei nicht zu verhindern, dass ab den 1990er Jahren in noch viel stärkerem Maße alternative Narrative zu „historischen Fehlern“ der Partei wie der Kampagne gegen Rechtsabweichler oder der Kulturrevolution entstanden als zuvor. Dies kann im Wesentlichen auf drei Gründe zurückgeführt werden:

- Erstens wurden die Repressionen, der sich die intellektuelle Gemeinschaft ausgesetzt sah, langsam, aber stetig wieder gelockert und auch die Zensurmaßnahmen nahmen wieder ab. Das hohe Maß an Repressionen konnte möglicherweise auch deshalb nicht dauerhaft aufrechterhalten werden, weil dies, wenn die Partei den Bogen überspannt hätte, zu einem noch größeren Verlust ihrer Herrschaftslegitimation geführt hätte. Und auch wenn das Maß der intellektuellen Freiheiten der 1980er Jahre nie mehr erreicht worden ist, wurden alternative Narrative zur Geschichte der VR China von den Behörden allmählich wieder zugelassen. Bezogen auf Veröffentlichungen zur Kampagne gegen Rechtsabweichler betraf dies zum Beispiel den Schriftsteller Zhang Xianliang. Dieser konnte bereits im Oktober des Jahres 1992, obwohl er gut drei Jahre zuvor noch ins Visier der chinesischen Zensurbehörden geraten war, seinen autobiografischen Roman Sorge ist Weisheit (Fannao jiushi zhihui 烦恼就是智慧) veröffentlichen. Dieser thematisiert das eigene Leid des Autors, dem er nach seiner Verurteilung als Rechtsabweichler im Laogai-System ausgesetzt gewesen war. Im Wesentlichen basiert er auf seinen Erinnerungen sowie seinen Tagebüchern, welche er im Jahr 1960 verfasst hatte, und ist dementsprechend auch aus der Ich-Perspektive geschrieben. Neben der Aufarbeitung des eigenen Traumas hat Zhang den Roman auch aus der Intention heraus geschrieben, dass zukünftige Generationen aus den Fehlern

414 Gruner 2004, S. 401. 
der Vergangenheit lernen sollten. ${ }^{415}$ Dass in den frühen 1990er Jahren nicht alles, was über den Erinnerungsrahmen der Resolution von 1981 hinausging, zensiert worden ist, zeigte sich auch anhand der von der KPCh aktiv tolerierten Gründung der Geschichtszeitung Yanhuang Chunqiu, deren Autoren von Beginn an einen alternativen Blick auf die jüngere Geschichte Chinas warfen.

- Zweitens wurde zunehmend deutlich, dass der offiziell festgelegte Erinnerungsrahmen der Resolution von 1981, die als Konsenspapier keineswegs die Gesamtmeinung der Partei hinsichtlich der Bewertung der eigenen Geschichte abbildete, nicht den gewünschten Schlussstrich unter die eigene schmerzhafte Vergangenheit der Partei zu ziehen vermochte - weder in der chinesischen Gesellschaft noch innerhalb der KPCh. Dies wurde insbesondere dadurch ersichtlich, dass sich ab den 1990er Jahren eine nicht geringe Anzahl ehemals hochrangiger Parteikader, die mit dem durch ihre Partei festgelegten Narrativ nicht einverstanden waren, aktiv an einer alternativen Geschichtsschreibung zu den „historischen Fehlern“ der KPCh beteiligten. Somit wurde das offizielle Narrativ gewissermaßen aus dem Inneren der Partei heraus angegriffen, wie im Folgenden genauer dargelegt wird. Anders ausgedrückt bekam die KPCh im Kampf um das kollektive Gedächtnis Konkurrenz aus den eigenen Reihen. Dies führte zudem dazu, dass die Narrative zur Kampagne gegen Rechtsabweichler nicht mehr nur durch Opferperspektiven geprägt wurden.

- Drittens stieg die Anzahl der von Zeitzeugen der Kampagne gegen Rechtsabweichler veröffentlichten Memoiren ab der zweiten Hälfte der 1990er Jahre massiv an. Wie Sebastian Veg darlegt, stellt insbesondere der 40. Jahrestag des Beginns der Kampagne gegen Rechtsabweichler im Jahr 1997 einen Wendepunkt im Umgang mit dieser dar, was eine Welle von Veröffentlichungen jenseits des offiziellen Narrativs nach sich zog. ${ }^{416}$ Zeitzeugen begannen in noch stärkerem Maße als zuvor damit, ihre persönlichen Erinnerungen $\mathrm{zu}$ teilen und in Form von Memoiren $\mathrm{zu}$ verbreiten. Dass dies ausgerechnet mit dem 40. Jahrestag der Kampagne zusammenfällt, korreliert auch mit der zuvor besprochenen Theorie Jan Assmanns, dass Zeitzeugen nach durchschnittlich etwa 40 Jahren das Bedürfnis verspüren, ihre Erinnerungen mit der nachfolgenden Generation zu teilen. ${ }^{417}$

415 Zhang 1994, S. 5.

416 Veg 2019, S. 86.

417 Assmann 2005, S. 51. 
Diese Entwicklungen führten dazu, dass in den 1990er Jahren ein regelrechter Erinnerungsboom ausgelöst worden ist. ${ }^{418}$ Und auch wenn die Fehler der Kampagne gegen Rechtsabweichler staatlich nicht aufgearbeitet wurden und auch keine offiziellen Erinnerungsorte entstanden sind, hat dennoch ein recht umfassender öffentlicher Diskurs um die Kampagne stattgefunden, welcher für sehr lange Zeit auch von staatlicher Seite toleriert worden ist.

Obwohl der offizielle Kanon mit der Veröffentlichung der offiziellen Mao-Biografie im Jahr 1996 wieder stärker betont wurde und die staatliche Erinnerungspolitik jener Jahre noch unter dem Eindruck der Patriotischen Bildungskampagne stand, war insbesondere die zweite Hälfte der Präsidentschaft Jiang Zemins von einem zunehmend liberalen Umgang mit den Intellektuellen geprägt. Diese durften sich relativ offen äußern - solange sie das Regime respektive die Herrschaftslegitimation nicht direkt herausforderten, ließ man sie gewähren. Riefen sie jedoch zum politischen Umbruch auf, wurden sie inhaftiert oder anderweitig ruhiggestellt. ${ }^{419}$ Die Intellektuellen traten auch deshalb nach und nach aus der Passivität heraus, in die sie nach 1989 gedrängt worden waren, weil sie, im Gegensatz zum China unter Mao, zunehmend unabhängiger vom Staat geworden waren - seit den 1980er Jahren sind auch außerhalb staatlicher Institutionen neue Beschäftigungsmöglichkeiten für Intellektuelle entstanden. Sie konnten nun als unabhängige Juristen, Journalisten, Kunstschaffende oder als Herausgeber in Verlagen arbeiten. ${ }^{420}$ Auch dies hat die Voraussetzungen dafür geschaffen, dass sich gegen Ende der 1990er Jahre somit nach und nach eine inoffizielle Geschichtsschreibung etablieren und alternative Versionen der Geschichte in zunehmendem Umfang innerhalb Chinas veröffentlicht werden konnten. ${ }^{421}$ Dies führte dazu, dass sich in den kommenden Jahren eine Reihe unterschiedlicher Akteure an der Neudeutung der Geschichte beteiligte, wie im Folgenden genauer dargelegt wird.

Hinzu kam ein weiterer Faktor, der dazu führte, dass sich offizielle Narrative zu den „historischen Fehlern“ der Partei nicht nachhaltig im kollektiven Gedächtnis festsetzten. Ab Mitte der 1990er Jahre spielte die Geschichte Chinas ab

418 Dieser Erinnerungsboom umfasste thematisch nicht ausschließlich die „historischen Fehler“ der KPCh, sondern betraf auch andere Themen wie den Krieg gegen Japan (1937-1945). Wie Susanne Weigelin-Schwiedrzik darlegt, lässt sich dies auf das Ende des Kalten Kriegs zurückführen, welches tiefgreifende Konsequenzen für die Geschichtsschreibung in Europa, aber auch in Ostasien nach sich gezogen habe. Dies habe demnach eine intensive Suche nach einem gemeinsamen Verständnis der Vergangenheit auf der Basis von Identität und Sicherheit nach sich gezogen, welche auch gegenwärtig noch nicht abgeschlossen ist. Weigelin-Schwiedrzik 2014, S. 2 f. 419 Goldman 1996, S. 49.

420 Veg 2019, S. 2.

421 Béja 2019, S. 25. 
1949 in den chinesischen Universitäten eine immer wichtigere Rolle. Auch das Interesse einer Reihe von Professoren an einer Neudeutung der Geschichte stieg damit erkennbar. Dies führte dazu, dass durch die verhältnismäßig großen wissenschaftlichen Freiheiten an Chinas Universitäten auch aus diesen staatlichen Institutionen heraus alternative Narrative zu den „historischen Fehlern“ der Partei entstanden sind. Teilweise beteiligten sich sogar Parteihistoriker aktiv an der Neudeutung einer Geschichte, die die Bewertung der Vergangenheit der Resolution von 1981 herausforderte. Luo Pinghan, einer der Autoren des in Kapitel 4 besprochenen im Jahr 2013 erschienenen Universitätslehrbuches, welches den von der Partei festgelegten Kanon wieder stärker förderte, setzte sich beispielsweise in seinem im Jahr 2003 erschienenen Buch Notizen zu Problemen der Zeitgeschichte (Dangshi lishi wenti zhaji 当时历史问题札记) äußerst kritisch mit der Kampagne gegen Rechtsabweichler auseinander. Wie einige seiner Kollegen in jenen Jahren auch, bewertet er die Bewegung darin nicht als richtig und notwendig, sondern ordnet sie eindeutig als „historischen Fehler“ ein, durch den nicht nur den Intellektuellen, sondern auch der Gesamtentwicklung Chinas massive und nachhaltige Schäden zugefügt worden seien. ${ }^{422}$

Neben der Kampagne gegen Rechtsabweichler weckten auch andere „historische Fehler“ der Partei das Interesse von einigen namenhaften Historikern. Neben der Landreform oder der Kulturrevolution gerieten dabei auch historische Ereignisse in den Fokus, die in der Resolution 1981 überhaupt keine Erwähnung gefunden hatten. Der über Chinas Grenzen hinweg bekannte und anerkannte Geschichtsprofessor der Peking-Universität Yang Kuisong beschäftigt sich in einem im Jahr 2006 erschienenen Artikel beispielsweise kritisch mit der Kampagne gegen Konterrevolutionäre (1950 - 53) - einer Kampagne, die durchaus Parallelen zu der rund sieben Jahre später initiierten Kampagne gegen Rechtsabweichler aufweist. ${ }^{423}$

Wie Kapitel 4 gezeigt hat, wurden diese kritischen und über den Kanon der KPCh hinausgehenden Bewertungen von sensiblen historischen Ereignissen in der Zeit rund um die Amtsübernahme Xi Jinpings zunehmend zum Dorn im Auge der Partei. Die staatliche Toleranz gegenüber einer solchen alternativen Geschichtsschreibung sank zunehmend und einige Wissenschaftler wie Luo Pinghan sollten sich spätestens ab dem Jahr 2012 wieder vorwiegend der Produktion und Verbreitung der durch die KPCh erwünschten Narrative widmen, was nicht nur das von Luo und anderen Wissenschaftlern im Jahr 2013 gemeinsam herausgegebene Universitätslehrbuch zur chinesischen Geschichte demonstriert.

422 Siehe Luo 2003, S. 40 ff. Vgl. Leutner 2007, S. 78 f.

423 Yang 2006. Zwei Jahre später veröffentlichte er auch einen Artikel zu diesem Thema auf Englisch, siehe Yang 2008. 
Hinsichtlich der Bewertung der Kampagne gegen Rechtsabweichler ist durch das Eintreten verschiedener Akteure in die aktive Geschichtsschreibung eine große Diversität entstanden. Dies hat zum einen dazu geführt, dass unterschiedliche Perspektiven - sowohl die Opfer- als auch die Parteiperspektive neue makro- und mikrohistorische Betrachtungen der Kampagne nach sich gezogen haben. Zum anderen ist im Laufe der Jahre eine Reihe ganz unterschiedlicher Textarten entstanden, von denen einige im Folgenden einer genaueren analytischen Betrachtung unterworfen werden. Während in den späten 1980er und den frühen 1990er Jahren vorwiegend Memoiren der Opfer veröffentlicht wurden, kamen später auch wissenschaftliche Texte oder das Genre der Reportageliteratur hinzu. So unterschiedlich diese Textformen der alternativen Geschichtsschreibung zur Kampagne gegen Rechtsabweichler auch sind, so unterschiedlich sind auch die darin erkennbaren Intentionen der Autorinnen und Autoren zur Veröffentlichung der Texte. Während es einigen um die objektive Darstellung der historischen Ereignisse der Jahre 1957 und 1958 und ihrer Folgen ging, ging es anderen wiederum um eine Aufarbeitung des eigenen Leids oder darum, dass einzelne Opfer nicht vergessen werden. All diese Texte weisen jedoch eine Gemeinsamkeit auf: Sie fordern mit ihrer kritischen Betrachtung der Vergangenheit die offizielle Geschichtsschreibung zur Kampagne gegen Rechtsabweichler heraus. Somit trugen sie auch dazu bei, dass sich der Kampf um Chinas kollektives Gedächtnis durch den von der Regierung Xi initiierten Kampf gegen den historischen Nihilismus zuspitzen würde.

\subsection{Die Neudeutung der Geschichte in Yanhuang Chunqiu 炎黄春秋}

Wie oben dargelegt, konnten die zunehmenden staatlichen Repressionen nach 1989 die Entstehung alternativer Narrative zu „historischen Fehlern“ der Partei nicht verhindern. Und so wurde bereits im Jahr 1991 von älteren Parteimitgliedern und pensionierten Funktionären die Geschichtszeitschrift Yanhuang Chunqiu gegründet. Die Gründer um Du Daozheng besaßen ein großes Netzwerk, das bis in die höchsten Parteikreise hineinreichte. Dies ermöglichte es ihnen auch, schnell eine offizielle Publikationslizenz (kan hao 刊號) zu erhalten, die es ihnen wiederum erlaubte, die Zeitschrift auf staatlich legitimiertem Wege legal zu verbreiten. Das Kernziel der Gründer der Zeitschrift war im Wesentlichen die Förderung einer Neudeutung der jüngeren Geschichte jenseits der offiziellen Interpretation der Resolution von 1981. Ihr großes Netzwerk verhalf ihnen auch dazu, Kontakte zu wichtigen Zeitzeugen wie ehemals hochrangigen Parteikadern aufzunehmen, die sich an dieser Form der Geschichtsschreibung beteiligen würden. Dabei 
sollten in den kommenden Jahren die sogenannten „historischen Fehler“, wie die Kampagne gegen Rechtsabweichler, der Große Sprung nach vorn oder die Kulturrevolution, eine wichtige Rolle spielen. Wu Si 吴思, der spätere Chefredakteur von Yanhuang Chunqiu, sagte im Jahr 2013 in einem Interview mit Jean-Philippe Béja, dass man in der Zeitschrift die „historischen Fehler“ der Vergangenheit aufzeigen wolle, um das Bewusstsein zu schärfen, dass es politischer Reformen bedarf und dass diese Form der Geschichtsschreibung eine Form der Demokratieförderung darstelle. ${ }^{424}$ Somit agierten die Redakteure durch die Gründung der Zeitschrift in der Tradition der Reformbewegung(en) der 1980er Jahre.

Zwischen den Jahren 1991 und 2016 sind insgesamt 1.148 Artikel zu den Themen Kampagne gegen Rechtsabweichler, Großer Sprung und Kulturrevolution erschienen. Vergleicht man dies mit der Gesamtzahl der in diesem Zeitraum in Yanhuang Chunqiu erschienenen 6.573 Artikel, machen die Artikel über diese „historischen Fehler“ 17,47 Prozent der inhaltlichen Schwerpunktsetzung aus. ${ }^{425}$ Davon beschäftigen sich 107 Artikel primär mit dem Großen Sprung, was, gemessen an der Gesamtzahl der Artikel, 1,63 Prozent entspricht und im Verhältnis zu den Artikeln zu den hier genannten „historischen Fehlern“ 9,32 Prozent ausmacht. Die Kulturrevolution stellt mit insgesamt 710 Artikeln den größten Teil der Artikel in der Kategorie „historische Fehler“ der KPCh, was einem Gesamtanteil von 10,8 Prozent aller Artikel in Yanhuang Chunqiu entspricht und 61,85 Prozent der Artikel zu den „historischen Fehlern“. Die Kampagne gegen Rechtsabweichler nimmt ebenfalls einen wichtigen Stellenwert in der Neudeutung der Geschichte in dieser Zeitschrift ein. Die 224 Artikel zu diesem Thema machen einen Gesamtanteil von 3,41 Prozent aller Artikel in Yanhuang Chunqiu aus, was wiederum 19,51 Prozent der Artikel zu den „historischen Fehlern“ der Partei entspricht. ${ }^{426}$

424 Béja 2019, S. 29.

425 Dies bedeutet keinesfalls, dass die Artikel zu den anderen Themen keine Kritik an der KPCh implizieren. Allerdings verlaufen die Grenzen zwischen kritischer und nichtkritischer Interpretation der Geschichte durch die Autoren häufig fließend, sodass sie sich nicht klar in die Kategorie „Berichterstattung über historische Fehler“ einordnen lassen. Thematisch sind diese Artikel sehr breit gefächert und reichen von der Geschichte der Partei während der 1930er Jahre über den SinoJapanischen Krieg bis hin zu Analysen zur Wirtschaftspolitik der VR China.

426 Zusätzlich sind noch 106 Artikel erschienen, die sich ebenfalls mit den Themen Kampagne gegen Rechtsabweichler, Großer Sprung oder Kulturrevolution beschäftigen, jedoch thematische Überschneidungen aufweisen und sich deshalb nicht eindeutig einem dieser drei Themen zuordnen lassen. Dies macht 9,32 Prozent der Artikel zu den Themen Kampagne gegen Rechtsabweichler, Großer Sprung und Kulturrevolution aus und entspricht einem Gesamtanteil von 1,61 Prozent. In den meisten Fällen handelt es sich um Kurzmemoiren von Zeitzeugen wie ehemalige Parteikader, die von ihrem Werdegang über einen längeren Zeitraum hinweg berichten. 
Dennoch stellte das Sprechen über die „historischen Fehler“ für die verantwortlichen Redakteure und für die Autoren von Yanhuang Chunqiu von Anfang an auch einen Ritt auf der Rasierklinge dar. Um ihre offizielle Veröffentlichungslizenz nicht zu verlieren und nicht fortan nur noch im Untergrund agieren zu können, mussten die leitenden Redakteure von Beginn an darauf achten, dass gewisse Grenzen nicht überschritten werden. Zum Beispiel durften sie weder offen zum politischen Umbruch aufrufen noch konnten sie $\mathrm{zu}$ detailliert darüber berichten, inwiefern noch aktive Politiker in die Planung und Umsetzung „historischer Fehler“ involviert gewesen sind. Dies war insbesondere deswegen heikel, weil eine Reihe von Autoren „historische Fehler“ in ihren Artikeln deutlich konkreter mit den Kategorien „historisches Verbrechen“ oder „historisches Unrecht“ verbunden hat als die Parteigeschichtsschreibung. Die Beschränkungen richteten sich somit auch nach den aktuellen politischen Umständen der jeweiligen Zeit, weshalb die Anzahl der Artikel zu den hier genannten „historischen Fehlern“ auch nicht gleichmäßig über die Jahre von 1991 bis 2016 verteilt sind. Insbesondere in den ersten Jahren nach der Gründung der Zeitschrift dürfte die Arbeit der Redakteure noch stark von den politischen Nachwirkungen der Ereignisse auf dem Platz des Himmlischen Friedens und den darauffolgenden politischen Restriktionen geprägt gewesen sein. Darauf deutet die Tatsache hin, dass im ersten Jahr der Veröffentlichung der Zeitschrift kein einziger Artikel zu den drei genannten Themen erschienen ist.

Dies bedeutet wiederum nicht, dass die Artikel der ersten Ausgaben völlig unkritisch gewesen sind. Der Auftakt der ersten Ausgabe stellte zum Beispiel eine kritische Auseinandersetzung mit dem Wirken Mao Zedongs dar. ${ }^{427}$ Allerdings war dies eher eine generelle, breit angelegte Kritik an Mao, als eine mikrohistorische Betrachtung einzelner Kampagnen. Erste Artikel zum Großen Sprung, insgesamt einer, und zur Kulturrevolution, insgesamt sieben, sind erst im darauffolgenden Jahr erschienen. ${ }^{428}$ Die Kampagne gegen Rechtsabweichler wurde erstmals mit der Märzausgabe des Jahres 1993 in einem Artikel erwähnt. Insgesamt sind in jenem Jahr fünf Beiträge zu diesem Thema erschienen. In den Jahren 1994 und 1995 kam das Thema, im Gegensatz zum Großen Sprung und zur Kulturrevolution, jedoch in keiner Ausgabe der Zeitschrift vor. Erst in den darauffolgenden Jahren kam die Berichterstattung zur Kampagne gegen Rechtsabweichler regelmäßig auf und nahm in einigen Jahren auch deutlich zu. In den Jahren 2010 und 2011 wurde sogar in jeder einzelnen Ausgabe mindestens ein Artikel zu diesem Thema ver-

427 Veg 2019, S. 113.

428 Im Jahr 1991 sind nur drei Ausgaben und im Jahr 1992 sechs Ausgaben erschienen. Ab dem Jahr 1993 ist die Zeitschrift dann regelmäßig jeden Monat erschienen. 
öffentlicht. Insgesamt nahm die Anzahl der Artikel zu den hier genannten „historischen Fehlern“ der Partei in den Jahren bis 2016 sukzessive zu, auch wenn sie immer wieder Schwankungen unterworfen war (siehe Tabelle 1). Ein Tabu wurde jedoch (fast) nie gebrochen: Das Tian'anmen-Massaker wurde in all den Jahren nur in einer einzigen Ausgabe, nämlich im August 2012, thematisiert. Die Vorfälle um den 04. Juni 1989 an sich werden überhaupt nicht beschrieben, sondern der Artikel bezieht sich eher auf die gesellschaftlichen Folgen der gewaltsamen Niederschlagung. ${ }^{429}$ Bemerkenswert ist jedoch, dass die Anzahl der Veröffentlichungen zu den drei statistisch untersuchten Themen auch nach der Amtsübernahme Xi Jinpings im Jahr 2013 nicht nennenswert zurückgegangen ist, obwohl er seinen Kampf gegen den historischen Nihilismus bereits im Jahr 2010 vorbereitet hatte. ${ }^{430}$ Die mangelnde Bereitschaft der leitenden Redakteure, die thematische Schwerpunktsetzung an die, aus Sicht der Partei, politischen Notwendigkeiten der 2010er Jahre anzupassen, hat letztlich wohl den entscheidenden Ausschlag gegeben, dass die chinesischen Behörden sich dazu veranlasst sahen einzugreifen.

Der Großteil der Artikel zur Kampagne gegen Rechtsabweichler zeichnet sich durch zwei wesentliche Merkmale aus: Die Autoren sind häufig ehemalige (hochrangige) Parteikader bzw. Parteimitglieder und die Artikel basieren zu einem nicht geringen Teil auf den Erinnerungen von Zeitzeugen. So spielt auch hier das individuelle Gedächtnis eine Schlüsselrolle in der inoffiziellen Geschichtsschreibung respektive im Kampf um das kollektive Gedächtnis.

Li Rui, zwischen 1958 und 1959 Maos Sekretär und Autor des bereits erwähnten ersten Artikels der ersten Ausgabe von Yanhuang Chunqiu, der sich kritisch mit Mao auseinandersetzt, war einer von ihnen. Das Bedürfnis, Zeugnis über die Geschichte abzulegen, hatte sich bereits mit der Veröffentlichung der Aufzeichnungen der Lushan-Konferenz 1959, welche die innerparteilichen Zerwürfnisse nach dem Großen Sprung dokumentierten, gezeigt. Aus dem innersten Zirkel der Macht heraus ist er bereits nach dem Großen Sprung zu einem Kritiker

429 Kaum ein Ereignis der Geschichte Chinas seit 1949 ist so tabuisiert wie die gewaltsame Niederschlagung der Studierendenproteste im Frühsommer 1989. Dies zeigte sich erneut rund um den 30. Jahrestag der Ereignisse am 04. Juni 2019, als die Zensurmaßnahmen der chinesischen Behörden einen neuen Höhepunkt erreichten. In Hongkong wurde jedoch eine Mahnwache gegen das Vergessen der Opfer abgehalten. Qin und Ramzy 2019, https://www.nytimes.com/2019/06/04/ world/asia/tiananmen-anniversary-china.html.

430 Der Rückgang im Jahr 2016 lässt sich darauf zurückführen, dass der Untersuchungszeitraum mit der Juliausgabe des Jahres 2016 endet, da dies die letzte Ausgabe vor der „staatlichen Übernahme“ und somit vor der Änderung der inhaltlichen Schwerpunkte der Zeitschrift war, sodass nur sieben Ausgaben für die Statistik berücksichtigt worden sind. Alle Ausgaben, die danach erschienen sind, fallen nicht mehr in die Kategorie „inoffizielle Geschichtsschreibung“. 


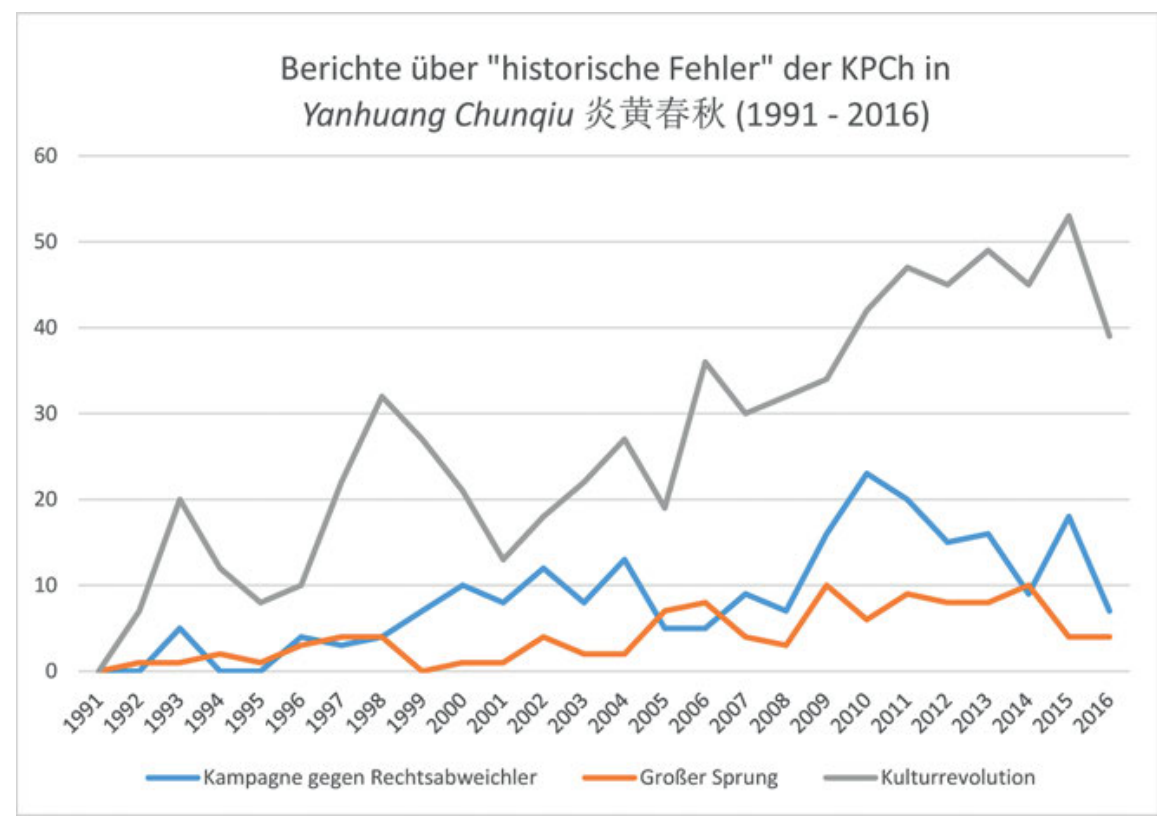

Tabelle 1: Berichte über „historische Fehler“ 1991-2016 (Quelle: eigene Erhebung, Yanhuang Chunqiu)

der „historischen Fehler“ der KPCh geworden. ${ }^{431}$ Insbesondere ab den 1990er Jahren veröffentlichte er eine Reihe von Büchern, in denen er sich kritisch mit der Geschichte der KPCh und Mao Zedong auseinandersetzte. Der Großteil dieser Bücher bewegte sich jedoch nicht mehr innerhalb der Grenzen der staatlichen Toleranz und konnte somit nur außerhalb der VR China veröffentlicht werden. ${ }^{432}$

Auch nach dem Beginn der Reform- und Öffnungspolitik äußerte er bis zu seinem Tod im Februar 2019 immer wieder Kritik an der Führung der KPCh. Diese Kritik beinhaltete auch den Umgang der KPCh mit ihrer eigenen Geschichte und die staatliche Unterdrückung von abweichenden Meinungen. Am 01. Oktober 2010 veröffentlichten er und 22 weitere Personen einen offenen Brief an den Ständigen Ausschuss des Nationalen Volkskongresses. Neben Li Rui befanden sich

$431 \mathrm{Li}$ Rui wurde deshalb nach der Lushan-Konferenz aus der Partei ausgeschlossen. Bis zum Jahr 1976 verbrachte er zudem immer wieder einige Zeit im Gefängnis bzw. im Laogai-System. Im Jahr 1979 wurde er schließlich rehabilitiert und im Zuge dessen wieder in die Partei aufgenommen. 1983 wurde er sogar Mitglied des Zentralkomitees der KPCh. Siehe Li 1995, S. $103 \mathrm{ff}$.

432 Darunter fiel beispielsweise das im Jahr 1993 in Hongkong erschienene Buch Die Verdienste und Fehler Mao Zedongs. Siehe Li 1993. 
unter den Unterzeichnern des Briefes einige sehr bekannte (ehemalige) Wissenschaftler und Journalisten, wie etwa Hu Jiwei 胡绩伟, in den 1980er Jahren Herausgeber der Renmin Ribao, oder Wang Yongcheng 王永成, damals Professor an der Jiaotong-Universität in Shanghai. In ihrem Brief forderten sie ein Ende der Beschränkungen der Meinungsfreiheit in China. Sie bezogen sich dabei auf den Artikel 35 der Verfassung der VR China, die eigentlich die Rede-, Presse- und Versammlungsfreiheit sowie das Demonstrationsrecht garantiert. Eine konsequente Umsetzung dieses Artikels könne demnach nur das Ende der Zensur bedeuten. Ihre Forderungen schlossen auch einen offenen Umgang mit den „historischen Fehlern“ der Partei mit ein, denn ihrer Meinung nach hätten die Bürger Chinas ein Recht darauf zu erfahren, welche Fehler die Partei gemacht hat, von der sie regiert werden. ${ }^{433} \mathrm{Li}$ Rui veröffentlichte auch kurz vor dem XIX. Parteitag der KPCh einen öffentlichen Brief, in dem er den Personenkult um Xi Jinping und die sich weiter verschärfenden Zensurmaßnahmen kritisierte. In seiner Kritik am neu aufflammenden Personenkult zog er auch einen Vergleich zwischen Xi Jinping und Mao Zedong. ${ }^{434}$

Diese kritische Haltung lässt sich eindeutig auch in seinen Beiträgen in Yanhuang Chunqiu erkennen, die er trotz des Veröffentlichungsverbots seiner Bücher innerhalb der VR China in dieser Form somit dennoch kundtun konnte. In einer seiner frühen Veröffentlichungen in dieser Zeitschrift erörtert er etwa, dass die größten „historischen Fehler“ der Partei dadurch entstanden seien, dass diese zu weit nach „links“ gerückt sei. Denn während sich die Partei zwischen 1949 und 1957 nach Meinung Li Ruis durchaus noch auf einem richtigen Weg befunden habe und auch einige Erfolge erzielt werden konnten, sei sie danach jedoch zu weit nach links abgedriftet und habe aufgrund dessen schwerwiegende Fehler begangen. Die Kampagne gegen Rechtsabweichler ordnet er in diesem Zusammenhang, ebenso wie den Kampf gegen die Intellektuellen bis zum Ende der 1970er Jahre im Allgemeinen, eindeutig als „historischen Fehler“ ein. Dementsprechend plädiert Li Rui dafür, aus der Geschichte insgesamt und insbesondere aus den Erfahrungen der 1950er Jahre zu lernen. Gleichzeitig betont er, dass Deng Xiaoping ab dem Ende der 1970er Jahre einen korrekten Pfad eingeschlagen und Ordnung aus dem Chaos der Kulturrevolution geschaffen habe. Dennoch macht er diesbezüglich eine Einschränkung, wonach linke Strömungen innerhalb der Partei und linke Fehler auch nach dem Beginn der Reform- und Öffnungspolitik

433 Bandurski 2010, http://chinamediaproject.org/2010/10/13/translation-the-october-11-letterfrom-party-elders/.

434 Huang und Mai 2019, https://www.scmp.com/news/china/politics/article/2186435/mao-ze dongs-personal-secretary-and-biggest-critic-li-rui-dies. 
weiterhin aufgetreten seien. Als Beispiel benennt er hier unter anderem die Kampagne gegen geistige Verschmutzung des Jahres 1983. Die gewaltsame Niederschlagung der Studierendenproteste des Jahres 1989 benennt er hingegen explizit nicht. Dennoch wirft er die Frage auf: „Warum wiederholt sich die historische Situation erneut?“435

Als zentrales Problem seit den 1950er Jahren sieht Li Rui in diesem Zusammenhang die theoretischen und praktischen Fehler in der Umsetzung des Marxismus, wie etwa die jahrelange Beschränkung auf den Klassenkampf oder die Beseitigung des Privateigentums, wodurch letztlich eine Stagnation in der praktischen Weiterentwicklung des Marxismus eingetreten sei:

\begin{abstract}
Marxismus ist Wissenschaft. Wissenschaft ist Entwicklung und sie kann nicht stagnieren (ebenso wie die Wahrheit). Das Wesen des Marxismus besteht darin, die Wahrheit in den Tatsachen zu suchen. Man kann sagen, dass jede Ära eine eigene Form des Marxismus hat. Wir können also nicht Marx, Lenin oder Stalin die Schuld geben, wir können nur uns selbst die Schuld geben. Darüber hinaus haben wir uns nicht an die grundlegenden Prinzipien des Marxismus gehalten: Das Fundament der Entwicklung der Menschheitsgeschichte sind Produktivität und Wirtschaftsinstitutionen und nicht der Überbau, der diesen nur entgegenwirken kann. Aber in der Dekade der „Kulturrevolution“ haben wir all dies auf den Kopf gestellt. ${ }^{436}$
\end{abstract}

Dementsprechend plädiert er dafür, weiterhin am Marxismus als ideologischer Grundlage Chinas festzuhalten, diesen jedoch immer wieder an die politischen und gesellschaftlichen Bedürfnisse der jeweiligen Zeit anzupassen. Somit argumentierte er, ebenso wie einige Intellektuelle in den späten 1970er und den frühen 1980er Jahren, in seinen Forderungen nach politischen Veränderungen und seiner alternativen Betrachtung der Geschichte der KPCh nicht im Widerspruch, sondern im Einklang mit dem Marxismus.

Parallelen zu den Veröffentlichungen der späten 1970er Jahre, wie etwa der Essay Hu Pings, lassen sich hier auch insofern feststellen, als dass er in seinen kritischen Ausführungen innerhalb dieses Artikels weder offen zu einer Kritik an den führenden Köpfen des post-maoistischen Chinas anhebt, noch die Herrschaftslegitimation der Partei in Frage stellt. Vielmehr mildert er seine kritischen Äußerungen immer wieder dadurch ab, dass er die Richtigkeit der politischen Reformen Deng Xiaopings betont:

Die Primärstufe des Sozialismus können wir nur durch die Marktwirtschaft aufbauen. Dies ist der entscheidende Durchbruch der Deng-Xiaoping-Theorie. Die größte Überlegenheit des

435 Eigene Übersetzung. Original siehe Li 1997, S. 4.

436 Eigene Übersetzung. Original siehe ebd., S. $4 \mathrm{f}$. 
Sozialismus besteht in der Schaffung eines gemeinsamen Wohlstandes und der Vermeidung der gesellschaftlichen Spaltung (dem Streben nach sozialer Gerechtigkeit); die Praxis der letzten beiden Jahrzehnte beweist die Richtigkeit der Deng-Xiaoping-Theorie. Natürlich wird sich mit der Entwicklung dieser Praxis auch die marxistische Theorie weiterentwickeln. ${ }^{437}$

Li Rui resümiert jedoch, dass man die historischen Erfahrungen der vergangenen 20 Jahre insgesamt analysieren müsse, um linke Fehler zukünftig zu vermeiden, und impliziert damit auch eine versteckte Kritik an den politischen Führern des post-maoistischen Chinas. Zur Beantwortung der Frage „Wie kann unsere Partei Demokratie und Rechtsstaatlichkeit weiter verbessern?““,438 müsse demnach unter anderem auch das Studium der modernen chinesischen Geschichte gefördert werden.

Dieser Artikel steht dabei exemplarisch für eine Reihe weiterer Beiträge in Yanhuang Chunqiu, in denen nicht nur eine alternative Betrachtung der „,historischen Fehler“ der KPCh, sondern (implizit) auch Forderungen nach politischen Veränderungen in der Gegenwart diskutiert werden. Sebastian Veg führt aus, dass die Gründer der Zeitschrift die Flammen der Demokratiebewegung der 1980er Jahre am Brennen halten wollten. ${ }^{439}$ Das Kredo ,aus der Vergangenheit lernen“ nimmt dabei einen zentralen Stellenwert in den (versteckten) Forderungen nach weiteren politischen Reformen ein.

Insbesondere für die Neudeutung der Geschichte der Kampagne gegen Rechtsabweichler in Yanhuang Chunqiu nimmt Li Rui einen wichtigen Stellenwert ein. Zwischen Dezember 1997 und Mai 2015 veröffentlichte er insgesamt sechs Beiträge, in denen er sich konkret mit den historischen Ereignissen der Jahre 1957 und 1958 auseinandersetzt. ${ }^{440}$ Dabei beleuchtet er sowohl mikro- als auch makrohistorische Zusammenhänge der Kampagne gegen Rechtsabweichler; das heißt, er lässt in seine Artikel konkrete Einzelschicksale ebenso mit einfließen wie die großen Zusammenhänge um die Ursachen, den Ausbruch und den Verlauf der Kampagne.

In einem Artikel in der Septemberausgabe des Jahres 2002 berichtet er zum Beispiel von dem Schicksal der Mitarbeiter der Neuen Hunaner Zeitung (xin Hunan bao 新湖南报). Während der Kampagne gegen Rechtsabweichler wurden im Jahr 195754 der rund 100 Mitarbeiter als Rechtsabweichler gebrandmarkt, woraufhin sie nicht nur ihre Anstellung verloren, sondern auch durch Arbeit umerzogen

437 Eigene Übersetzung. Original siehe ebd., S. 5.

438 Eigene Übersetzung. Original siehe ebd., S. 9.

439 Veg 2019, S. 113.

440 Hinzu kamen noch zahlreiche weitere Artikel, die über dieses Thema hinausgehen und sich mit der Geschichte Chinas seit den 1920er Jahren beschäftigen. 
wurden. Gemäß den Untersuchungsergebnissen dieser Fälle, die direkt nach der 3. Plenarsitzung des 11. Zentralkomitees im Dezember 1978 angestoßen worden waren, sind alle 54 Mitarbeiter zu Unrecht verurteilt worden und ihre Fälle mussten korrigiert werden. Li Rui weist darauf hin, dass er bereits vor einigen Jahren auf den Fall der Mitarbeiter der Zeitung aufmerksam geworden sei und er den Betroffenen geraten habe, ihre Einzelschicksale zu dokumentieren und so für die Nachwelt festzuhalten. Li betont auch hier, dass es besonders wichtig sei, dass zukünftige Generationen Lehren aus der Geschichte ziehen. ${ }^{441}$

Anhand der Einzelschicksale der Mitarbeiter der Zeitung gewinnt Li Rui in seinem Artikel größere Erkenntnisse zu den Folgen der Kampagne gegen Rechtsabweichler. Diese beschreibt er eindeutig als katastrophal. Außerdem sieht er in der Kampagne gegen Rechtsabweichler einen historischen Wendepunkt, der die politische Leitlinie der KPCh in den kommenden Jahren nachhaltig verändert und somit beispielsweise auch die Voraussetzungen für die Katastrophe des Großen Sprungs geschaffen habe:

Nach 20 Jahren der Reform sehe ich rückblickend klarer: Erstens, der Kampf gegen die Rechten hat die Linie verändert, welche durch den XIII. Parteitag der KPCh beschlossen worden war, und führte zu einer Rückkehr zum Pfad des Klassenkampfes. Zweitens wurde das Sprechen kriminalisiert. Keiner wagte es mehr, einen Kommentar abzugeben, sodass der darauffolgende „Große Sprung nach vorn“ weitgehend ohne Kritik durchgeführt wurde. Drittens, einige Ideen zur Stärkung der sozialistischen Demokratie und des sozialistischen Rechtssystems sowie einige Ideen, die zur Entwicklung der Produktivkräfte hätten beitragen können (wie etwa die Einführung ausländischen Kapitals und dass Kader über professionelle Kenntnisse verfügen usw.), wurden alle als falsch kritisiert, sodass Richtig und Falsch verdreht wurden, der Aufbau der sozialistischen Demokratie Schaden nahm und das Rechtssystem die Entwicklung der Produktivkräfte gefährdete. Viertens, einige Leute verbreiteten Lügen und begingen Verrat an einem Freund; wenn die Schläger und diejenigen, die Steine schmeißen, und diejenigen mit einem starken Einfluss befördert und belohnt werden, ruiniert dies die Moral einer Gesellschaft. Dies war eine groß angelegte, umgekehrte Eliminierung der Kadertruppe, welche deren durchschnittliches ethisches und professionelles Niveau sinken ließ und der Sache langfristigen Schaden zufügte. Wenn wir über die Rolle der Kampagne gegen Rechtsabweichler in der Geschichte sprechen, müssen wir dies von diesem Blickwinkel und dieser Ebene aus tun, um der Realität näher zu kommen. ${ }^{442}$

Somit verknüpft er die Geschichte um die Einzelschicksale mit einem weiteren Blickwinkel auf die Ereignisse um die Kampagne gegen Rechtsabweichler sowie einige andere historische Ereignisse der darauffolgenden Jahre.

441 Ende des Jahres 2002 wurden diese dokumentierten Einzelschicksale schließlich von Zhu Zheng 朱正in China unter dem Titel 1957: Die Mitarbeiter der Neuen Hunaner Zeitung (1957: 新湖南 报人) als Buch herausgegeben. Das Buch ist gegenwärtig in China nicht mehr legal verfügbar. 442 Eigene Übersetzung. Original siehe Li 2002a, S. 2. 
Darüber hinaus betrachtet Li Rui in einigen seiner Artikel die Geschichte um den Kampf gegen die Rechten nicht isoliert, sondern setzt die Ereignisse der Jahre 1957 und 1958 in größere historische Zusammenhänge. Dies wird insbesondere in einem Artikel der Juliausgabe des Jahres 2008 deutlich. In diesem erörtert er, dass die Kampagne gegen Rechtsabweichler kein Zufall gewesen sei, sondern im Zusammenhang mit Mao Zedongs genereller Haltung gegenüber den Intellektuellen gesehen werden müsse, welche weitreichende historische Wurzeln habe. Somit beschäftigt er sich im Gegensatz zu einer Vielzahl anderer Zeitzeugen oder Historiker auch nicht mit der Frage, ob die Kampagne gegen Rechtsabweichler eine Falle gewesen ist oder nicht, Li Rui sieht in ihr vielmehr eine logische Konsequenz, die aus der persönlichen und beruflichen Biografie Maos resultiere. Demnach habe Mao bereits zu Beginn seiner Karriere im Jahr 1919 tiefe Vorurteile gegenüber Intellektuellen erkennen lassen, unter anderem weil er sich nach seiner Ankunft in Peking von einigen von ihnen herabgesetzt gefühlt habe. Li Rui stützt sich in seiner Argumentation unter anderem auf Maos Aussagen, die er 1936 seinem Biografen Edgar Snow gegenüber getätigt haben soll. ${ }^{443}$

Li Rui argumentiert, dass Mao von seiner in den 1920er und 1930er Jahre entwickelten Haltung gegenüber den Intellektuellen bis zum Ende seines Lebens nicht mehr grundlegend abgerückt sei, was die Politik der kommenden Jahrzehnte entsprechend beeinflusst habe. Dies habe sich bereits kurz nach der Gründung der VR China etwa in Form der Kampagne gegen Konterrevolutionäre (1950 - 53) oder der Kampagne gegen den „Konterrevolutionär“ Hu Feng 胡风 und seine Anhänger in Jahr 1955 gezeigt. ${ }^{444}$ Hier lässt Li Rui in seine Ausführungen auch seine persönlichen Erfahrungen und seine Erinnerungen an die späten 1950er Jahre miteinfließen:

Später wurde die „Bewegung gegen die versteckten Konterrevolutionäre“ durchgeführt und viele Intellektuelle, die noch aus vorangegangenen Bewegungen „historische Probleme“ hatten, wurden zu Zielen dieser Bewegung. Zu dieser Zeit hatte ich Zweifel an der Bewegung gegen Hu Feng und sprach mit meinen Kollegen darüber. Nach der Lushan-Konferenz 1959 wurde ich dann aus der Partei ausgeschlossen, das ist eines der „Verbrechen“. 445

Somit sei der Kampf gegen die Intellektuellen stetig fortgeführt worden und habe im Jahr 1957 schließlich seinen Höhepunkt gefunden. Die Verantwortung für den stetigen Kampf gegen Intellektuelle seit Gründung der VR China, und ins-

443 Die Biografie „Roter Stern über China“ ist im Jahr 1937 auf Englisch und im gleichen Jahr auch auf Deutsch erschienen. Edgar Snow sollte durch die Biografie Maos Ideen auch dem Westen zugänglich machen. Siehe Snow 1986.

444 Zum Prozess gegen die sogenannte Hu-Feng-Clique siehe Li 2003.

445 Eigene Übersetzung, siehe Li 2008a, S. 28. 
besondere auch für die Kampagne gegen Rechtsabweichler, schreibt er einzig und alleine Mao Zedong zu. Deng Xiaopings Rolle bleibt hier, ebenso wie in allen anderen Artikeln Li Ruis zu dieser Thematik, komplett unerwähnt. Allerdings impliziert seine kritische Auseinandersetzung mit dem Umgang mit den Intellektuellen teilweise durchaus auch eine kollektive Schuldzuweisung an die Partei; das heißt, er deutet immer wieder an, dass die Partei mit nur wenigen Ausnahmen Maos Kampf gegen die Intellektuellen durchaus auch mitgetragen habe. Als Beispiel nennt er hier die falschen theoretischen Grundlagen im Umgang mit den Intellektuellen, die den Kampf gegen sie noch verschärft hätten. Demnach sei, so Li Rui, die kategorische Einordnung der Intellektuellen in die bürgerliche Kategorie ein Fehler gewesen, da in der Regel unberücksichtigt geblieben sei, dass einige von ihnen auch aus Familien von Arbeitern und Bauern stammten. ${ }^{446}$

Li Rui stellt in dem Artikel außerdem heraus, dass die Geschichte nicht einem Selbstzweck diene, sondern, dass eine Auseinandersetzung mit den „historischen Fehlern“ seit 1949 wichtig sei, um aus diesen für die Zukunft zu lernen. Und somit geht auch hier, wie in vielen weiteren Artikeln in Yanhuang Chunqiu, die Auseinandersetzung mit den „historischen Fehlern“ der KPCh mit einer Verknüpfung mit aktuellen politischen Forderungen einher:

Nach mehr als zwei Jahrzehnten der Reform und Öffnung, mit einem Verständnis der Weltlage und dem Rückblick auf historische Ereignisse wie den Kampf gegen die Rechten, konnten wir ein klareres und tieferes Verständnis erlangen. Welche Meinungen haben die Rechten in jenem Jahr, ${ }^{447}$ von oben bis unten, öffentlich kundgetan? Gegenwärtig werden eine Reihe von Artikeln und Büchern veröffentlicht, die sich auf Erinnerungen beziehen, und ich habe noch keinen Beitrag gesehen, der zeigt, dass damals die Idee verbreitet worden ist, die KPCh stürzen zu wollen, ganz im Gegenteil, enthielten sie alle möglichen sachlichen Vorschläge zur Verbesserung der Führung der Partei; genauso, wie wir auch heute eine Politik anstreben, in der wir über Demokratie und Rechtsstaatlichkeit sprechen, um unsere Gesellschaft gerechter und harmonischer zu machen, und in der wir den Empfehlungen der Intellektuellen mehr Aufmerksamkeit entgegenbringen wollen. Denn wenn ihre Empfehlungen damals angenommen worden wären, wie hätte der „Große Sprung“, die dreijährige Hungersnot und die Kulturrevolution überhaupt stattfinden können? Wie hätten dann zig Millionen Menschen sterben und die Intellektuellen zu den „alten Neun“ werden können und hätte man überhaupt gesagt ,je intellektueller, desto dümmer und reaktionärer“? Rückblickend sind die 30 Jahre zwischen 1949 und 1979 global die Periode der schnellsten und größten wissenschaftlichen und wirtschaftlichen Entwicklung im 20. Jahrhundert und gingen damit auch in Richtung einer Ära einer wissensbasierten Wirtschaft; wir hingegen haben uns im völligen Widerspruch dazu entwickelt, das Land wäre fast kollabiert und musste einen langen Weg gehen; es ist wirklich bedrückend, darüber nachzudenken. Nach der Zerschlagung der „Viererbande“ berief das ZK der KPCh die 3. Plenarsitzung des

446 Ebd., S. 29.

447 Anm.: Im Jahr 1957. 
11. Zentralkomitees ein, bei der unsere Partei nach und nach erkannt hat, dass die gesellschaftlichen und historischen Fortschritte nicht auf „Klassenkampf“ und „Klassendiktatur“, sondern hauptsächlich auf Wissen und wissenschaftlichen Erkenntnissen, das heißt auf menschlicher Intelligenz beruhen; dies ist die wichtigste, grundlegende Triebfeder, deren Träger Intellektuelle sind, insbesondere große Intellektuelle! $!^{448}$

Für eine positive Gestaltung der Zukunft Chinas nehmen die Intellektuellen für Li Rui also eine Schlüsselposition ein.

Ein weiterer ehemaliger hochrangiger Parteikader, der sich an der Neudeutung der Kampagne gegen Rechtsabweichler in Yanhuang Chunqiu beteiligte, ist Li Shenzhi 李慎之. Li war zum Ende der Kulturrevolution Sekretär für Auswärtige Angelegenheiten unter Zhou Enlai und nach Beginn der Reform- und Öffnungspolitik kurzzeitig außenpolitischer Berater Deng Xiaopings. Ab dem Jahr 1980 baute er an der CASS das USA-Forschungsinstitut auf und wurde 1985 schließlich zum Vizepräsidenten der CASS ernannt. Während dieser Zeit nahm er nach und nach einen kritischeren Blick auf die KPCh und ihre Geschichte ein. Als er die Studierendenproteste 1989 unterstützte, wurde er schließlich seines Postens enthoben. Seitdem übte er immer wieder öffentlich Kritik an der Partei und setzte sich für eine Demokratisierung Chinas ein. ${ }^{449}$

Zwischen 1999 und 2013 veröffentlichte er insgesamt fünf Artikel zur Kampagne gegen Rechtsabweichler in Yanhuang Chunqiu, wobei zwei davon erst nach seinem Tod im Jahr 2003 erschienen sind. Zusätzlich dazu veröffentlichte er zu Lebzeiten noch diverse weitere Artikel zu unterschiedlichen Themen. Auch hier erfolgte der Blick auf die Geschichte aus dem inneren Zirkel der Macht heraus, denn nachdem er 1944 der KPCh beigetreten war, hat er die „historischen Fehler“ der Partei auch durch seine engen Kontakte zu Entscheidungsträgern der damaligen Zeit aus einem besonderen Blickwinkel erlebt. Doch auch Lis ganz persönliche Erfahrungen spielten eine wichtige Rolle für seine Neudeutung der Vergangenheit, da er 1957 selbst zum Rechtsabweichler verurteilt worden war. Auch wenn er als einer der wenigen bereits nach recht kurzer Zeit rehabilitiert worden ist, in die Gesellschaft zurückkehren und seine Parteiarbeit wieder aufnehmen konnte, prägten diese Erfahrungen seinen kritischen Blick auf die Partei entscheidend, auch wenn er beruflich einige Jahre eng in das System eingebunden war.

In seinen Artikeln beleuchtet er die Kampagne gegen Rechtsabweichler auf sehr vielschichtige Weise und betrachtet dabei, ebenso wie Li Rui, die Geschichte sowohl auf einer Mikro- als auch auf einer Makroebene und nimmt im Zuge dessen

448 Eigene Übersetzung. Original siehe ebd., S. 31.

449 Ching 2003, https://www.scmp.com/article/414767/li-shenzhi-revolutionary-and-democrat. 
auch eine Neudeutung der Geschichte vor. In seinem ersten Artikel aus der Januarausgabe des Jahres 1999 setzt er sich sogleich mit der Frage auseinander, ob die Intellektuellen durch die Hundert-Blumen-Bewegung ab Mitte Mai 1957 in eine von Mao gelegte Falle gelockt worden seien oder nicht. Er stellt die These auf, dass der Kampf gegen die Rechten als eine lang geplante Verschwörung angesehen werden könne, die bereits ab Ende Januar allmählich in die Tat umgesetzt worden sei. Li Shenzhi legt dar, dass das vorangegangene Jahr 1956 für China eigentlich ein sehr erfolgreiches gewesen sei, da China in jenem Jahr endgültig in den Sozialismus eingetreten sei. Dennoch habe der Sturm, der in Form der Geheimrede Chruschtschows und der Volksaufstände in Polen und Ungarn durch die kommunistische internationale Gemeinschaft gegangen sei, einen plötzlichen politischen Kurswechsel im Umgang mit den Intellektuellen in China verursacht. Aus Angst, dass sich solche Ereignisse in China wiederholen könnten, habe Mao deshalb damit begonnen, sukzessive „die Schlangen aus ihren Löchern zu holen“. Li ist der Ansicht, dass die Planungen dafür sogar bereits mit der 2. Plenarsitzung des 8. Zentralkomitees, welche im Zeitraum 10.-15. November 1956 in Peking abgehalten worden war, begonnen hätten:

Daher lauten meine Erkenntnis und mein Urteil: Der Einsatz der Strategie „die Schlangen aus ihren Löchern holen“ wurde während der 2. Plenarsitzung des 8. Zentralkomitees eingeleitet und es wurde beschlossen, dies auch während einer Zeitspanne von zwei Monaten in die Parteikomiteesitzungen auf Provinz- und Stadtebene weiterzutragen. Dieses Vorgehen entsprach den Gewohnheiten des Vorsitzenden Mao, große Entscheidungen zu treffen, was man auch als „Strohsandalen brauchen keine Leisten, die Form kommt beim Flechten“ bezeichnen kann. Das, was er dann fünf Monate später ab dem 08. Juni tat, das war „den Köder richten, um die Goldfische zu fangen“. ${ }^{450}$

Bemerkenswert an Li Shenzhis Artikel ist, dass in diesem zwar die strategische Planung und Durchführung der Kampagne im Fokus steht, Deng Xiaopings Rolle in dieser, wie schon in den Artikeln Li Ruis, jedoch keine Erwähnung findet.

Ebenso wie viele andere Akteure der Geschichtsschreibung der hier beschriebenen Kategorie, sieht Li Shenzhi in der Kampagne gegen Rechtsabweichler einen zentralen Wendepunkt in der Geschichte der VR China, der die Grundlagen für das Desaster des Großen Sprungs und für die Kulturrevolution gelegt habe, welche wiederum auf der Idee der „Widersprüche im Volk“ (renmin neibu maodun 人民内部矛盾) beruhe. Er geht sogar noch weiter und legt dar, dass mit der Kampagne gegen Rechtsabweichler eine Neuordnung der sozialen Klassen entstanden sei:

450 Eigene Übersetzung. Original siehe Li 1999b, S. 11. 


\begin{abstract}
Das einzig Neue daran ist, dass durch die „Widersprüche im Volk“ und die Kampagne gegen Rechtsabweichler ein Lösungsmodell für den Umgang mit eben jenen „Widersprüchen im Volk“ vorgeschlagen wurde; der Vorsitzende Mao hat sich eine Theorie ausgedacht, wonach die Menschen nicht mehr entsprechend ihres Stands der Produktionsbeziehungen, sondern gemäß ihrer ideologischen Klasse eingestuft würden. Später wurde es zur Norm, die Klassen in eine mit und eine ohne Mao-Zedong-Ideen zu unterteilen; Erstere war das Proletariat und Letztere war die Bourgeoise. Aus diesem Grund wurden viele Kommunisten, die eigentlich die Vorhut des Proletariats bildeten, zu rechten Elementen der Bourgeoisie, und deshalb sind viele von ihnen als die „drei Widerparte“ (gegen die Partei, gegen den Sozialismus und gegen die Mao-Zedong-Ideen) während der Kulturrevolution in Erscheinung getreten, obwohl es tatsächlich nur sehr wenige gab, die wirklich „oppositionell“ gewesen sind. ${ }^{451}$
\end{abstract}

Seine eigenen Erfahrungen und Erlebnisse als sogenannter Rechtsabweichler fließen immer wieder in seine historische Neudeutung der Kampagne ein. Dies wird insbesondere in einem Artikel, der in der Augustausgabe des Jahres 2003 kurz nach seinem Tode erschienen ist, deutlich. In diesem gedenkt er seinem einstigen Weggefährten Li Bingquan 李丙泉, mit dem er bis zu seiner Verurteilung als Rechtsabweichler acht Jahre lang in der Nachrichtenagentur Xinhua (xinhua tongxunshe 新华通讯社) zusammengearbeitet hatte. Er berichtet zunächst von jenen Tagen im September 1957, in denen er als Rechtsabweichler abgestempelt wurde. Bei einer Befragung durch die Parteikader zur ideologischen Gesinnung und zu eventuellen rechtsabweichlerischen Äußerungen Lis habe Li Bingquan demnach noch versucht, seinen Weggefährten zu verteidigen:

Im September 1957, als ich gerade wegen rechtsabweichlerischer Fragen kritisiert worden bin, ist Bingquan vermutlich gerade aus dem Ausland zurückgekehrt. Als mein enger Kollege konnte er nicht anders, als sich auch zu Wort zu melden. Ich erinnere mich noch an seinen ersten Satz: „In den letzten Jahren ist Li Shenzhi den Versammlungen ferngeblieben und blieb eher für sich; nachdem er den Reden der Genossen zugehört hatte, wusste er, dass sich seine Begeisterung zu einem sehr gefährlichen Level entwickelt hatte ..." Zu jener Zeit war ich wie ein Vogel in Gefangenschaft, der skeptisch darauf wartete, dass man auf ihn einschlägt, obwohl er bereits am Boden war; es war ziemlich wahrscheinlich, dass jederzeit jemand aufstehen könnte, um zu sagen: „In einem bestimmten Jahr, in einem bestimmten Monat, an einem bestimmten Tag hat Li Shenzhi etwas zu mir gesagt. Li Shenzhi, du musst dein schwarzes Programm erklären ...“ Als ich die einleitenden Bemerkungen Bingquans hörte, war ich erleichtert, denn ein solcher Mensch war er nicht. ${ }^{452}$

Dass er versuchte habe, ihm zu helfen, sei Li Shenzhi bei allen negativen Erinnerungen an die Erlebnisse jener Jahre positiv im Gedächtnis geblieben. Auch wenn ihm dies letztlich nichts nutzte, macht er mit diesem Artikel deutlich, dass

451 Eigene Übersetzung. Original siehe ebd., S. 13.

452 Eigene Übersetzung. Original siehe Li 2003b, S. 53. 
es während der Kampagne gegen Rechtsabweichler neben Denunziantentum auch Kameradschaft und Zusammenhalt gegeben habe.

In dem Artikel erinnert Li jedoch auch daran, dass Intellektuelle, sowohl während der Kampagne gegen Rechtsabweichler als auch während der Kulturrevolution, häufig ein ähnliches Schicksal erleiden mussten und buchstäblich über Nacht zu Feinden des Sozialismus respektive der Partei erklärt werden konnten, obwohl die meisten von ihnen eigentlich loyale Kommunisten gewesen seien. Li Bingquan, so berichtet es Li Shenzhi, sei während der Kulturrevolution ebenfalls ein solches Schicksal zuteilgeworden. Rund zehn Jahre nachdem Li Shenzhi zum Rechtsabweichler verurteilt worden war, sei Li Bingquan im Zuge des Sturms der Kulturrevolution als Kapitalist und Konterrevolutionär gebrandmarkt und daraufhin eingesperrt worden. Wie Li Shenzhi erst später erfuhr - er und Li Bingquan hatten seit seiner Verurteilung als Rechtsabweichler keinen Kontakt mehr -, starb sein alter Freund Bingquan am 02. Mai 1970. Seiner Familie wurde mitgeteilt, dass er sich das Leben genommen habe, jedoch merkt Li an, dass es auch Hinweise gegeben habe, wonach er möglicherweise von einem Parteikader umgebracht worden sein könnte. In seinen Abschlussworten wird die Intention Li Shenzhis deutlich, dass er von dem Schicksal seines Freundes auch deshalb berichten wolle, weil er die Hoffnung in sich trage, dass zukünftige Generationen ihre Lehren daraus ziehen und sich eine solche Tragödie, bei der Unschuldige sterben, zukünftig nicht wiederholen möge:

Unter den Freunden, die ich kenne, stellt Bingquan das typischste Beispiel für jemanden dar, der der Revolution loyal gegenüberstand und an der Revolution gestorben ist. Die obigen Worte aufzuschreiben, diente natürlich dem Zweck, Bingquan zu gedenken und auch meiner Trauer Ausdruck zu verleihen, gleichzeitig geht es mir jedoch auch darum, zukünftigen Generationen die Frage zu stellen, wie solche Tragödien zukünftig vermieden werden können. 453

Artikel wie dieser machen einen sehr großen Teil der Artikel zur Kampagne gegen Rechtsabweichler in Yanhuang Chunqiu aus. In diesen erinnern die Autorinnen und Autoren an ehemalige politische und berufliche Weggefährten oder an enge Familienangehörige, die der Kampagne zum Opfer gefallen sind. Die Betrachtung der Geschichte innerhalb dieser Artikel bezieht sich in Yanhuang Chunqiu meist nur auf eine kurze Episode innerhalb des jeweiligen historischen Ereignisses bzw. auf das Schicksal einer Einzelperson oder eines begrenzten Personenkreises. Texte wie dieser können deshalb auch als Kurzmemoiren bezeichnet werden. Sie beruhen auf dem individuellen Gedächtnis der Autoren selbst, aber auch auf den

453 Eigene Übersetzung. Original siehe ebd., S. 55. 
Erinnerungen, die die jeweilige im Text beschriebene Person an die nachfolgende Generation weitergegeben hat. Sie können als ein Akt gegen das Vergessen der Opfer angesehen werden und stellen somit gleichzeitig alternative Erinnerungsorte dar. Pierre Nora definiert einen Erinnerungsort als:

\footnotetext{
[...] materiellen wie auch immateriellen, langlebigen, Generationen überdauernden Kristallisationspunkt kollektiver Erinnerung und Identität, der durch einen Überschuss an symbolischer und emotionaler Dimension gekennzeichnet, in gesellschaftliche, kulturelle und politische Üblichkeiten eingebunden ist und sich in dem Maße verändert, in dem sich die Weise seiner Wahrnehmung, Aneignung, Anwendung und Übertragung verändert. ${ }^{454}$
}

In Ermangelung von Gedenkstätten oder anderen materiellen Erinnerungsorten zur Kampagne gegen Rechtsabweichler in der VR China spielen immaterielle Erinnerungsorte wie diese insofern für die Zeitzeugen bzw. die Opfer selbst eine sehr wichtige Rolle für die Aufarbeitung des Erlebten.

Auch Li Shenzhi wird nach seinem Tod zum Gegenstand der Texte gegen das Vergessen. In der Aprilausgabe des Jahres 2009 erinnert sein ehemaliger Weggefährte Dai Huang 戴煌 an das Wirken Li Shenzhis, mit dem er in den 1950er Jahren bis zur Kampagne gegen Rechtsabweichler in der Nachrichtenagentur Xinhua zusammengearbeitet hatte. Der Autor des Textes umreißt dabei nicht die gesamte Lebensgeschichte Li Shenzhis, sondern beschreibt insbesondere die Abschnitte seines Lebens, in denen sich die Lebenswege der beiden kreuzten. Dabei verarbeitet Dai Huang in diesem Artikel auch sein eigenes Schicksal, denn er wurde gleichzeitig mit Li Shenzhi zum Rechtsabweichler verurteilt. Im Gegensatz zu Li Shenzhi wurde er jedoch nicht nach wenigen Jahren wieder rehabilitiert, sondern verbrachte 21 Jahre im Laogai-System zur Umerziehung durch Arbeit. Dieser Artikel weist eine Besonderheit auf, da der Autor als einer der ganz wenigen ehemaligen Rechtsabweichler einräumt, die Partei im Jahr 1957 offen kritisiert und Maos Autorität in Frage gestellt zu haben. Besonders ausführlich berichtet Dai jedoch davon, dass Li Shenzhi, den er im Text nur Bruder Shenzhi nennt, ihn und seine Familie während und nach seinem Aufenthalt im LaogaiSystem finanziell unterstützt habe, waren sie doch aufgrund dessen völlig verarmt. Besonders ausführlich berichtet er von einer Begegnung in den 1960er Jahren, als Bruder Shenzhi ihn besucht, ihm Kleidung mitgebracht und etwas Geld für seine Familie gegeben habe:

Dann schnürte Bruder Shenzhi einen blauen Kleiderbeutel auseinander; es stellte sich heraus, dass er einen verblichenen grau-blauen Mao-Anzug enthielt und einen dazu passenden Hut. Er erzählte unserer Familie, dass, obwohl er aus der Partei ausgeschlossen

454 Franqois 2005, S. 9. 
worden war, sein Gehalt nur um ein paar Stufen gekürzt worden sei; er verdiente 90 Yuan pro Monat, zuzüglich der 100 Yuan, die Zhang Jies älteste Schwester nach Hause brachte; obwohl er nicht mehr so viel verdiente wie früher, konnte er dennoch etwas abgeben und es ging ihm dennoch besser als unserer Familie, die fast obdachlos war. ${ }^{455}$

Somit berichtet auch Dai Huang davon, dass es während der Kampagne gegen Rechtsabweichler durchaus noch Kameradschaft und Zusammengehörigkeit gegeben habe.

Insbesondere jedoch habe Li Shenzhi in ihm sein politisches Bewusstsein wieder zum Leben erweckt, war dieses doch, wie er anmerkt, nach 21 Jahren im Laogai-System und der politischen Indoktrination zunächst zum Erliegen gekommen. Insbesondere erinnere er sich an ein Gespräch mit Li, in dem sie, Bezug nehmend auf die Schriften Marx', über die Überwindung autoritärer Diktaturen sprachen:

Kurz gesagt hat das Gespräch zwischen Bruder Shenzhi und mir, insbesondere die Diskussion über die autoritäre Diktatur, wesentlich dazu beigetragen, dass ich mich der Erforschung solcher Themen widmen würde. Und wie ist es um die Realität unserer Partei bestellt, insbesondere bezüglich der historischen Fakten der ersten 30 Jahre nach Gründung der Volksrepublik, und um die Kommunisten, die nicht gewillt sind, ihr Gelübde zu brechen, das sie einst sprachen, als sie der Partei beigetreten sind? ${ }^{456}$

Wie hier bereits angedeutet wird, geht dieser Erinnerungstext, wie so viele Texte in Yanhuang Chunqiu, auch mit einer Forderung nach Aufarbeitung der Geschichte und indirekt auch nach politischen Reformen einher. Schließlich ruft Dai am Ende des Artikels dazu auf, dass sich Lis noch lebenden Zeitgenossen und die nachfolgenden Generationen dafür einsetzen, die von Li Shenzhi in den Jahren vor seinem Tode formulierten Forderungen umzusetzen:

Ja, es ist eine Schande! Es ist nicht nur nicht so, dass wir die „erzwungene Autokratie“ (nach Zeng Yanxius Trauer) nicht sehen können, es ist umso bedauerlicher, dass er die Verwirklichung seines im In- und Ausland gepriesenen Textes „50 Jahre Wind und Regen“ nicht erleben konnte und seine Wünsche zu einem fortwährenden Bedauern gemacht wurden. Das ist genau das „Spiegelbild der Kulturrevolution und von da an ein Umdenken der 30-jährigen Autokratie ... eine Wiedergeburt und eine Aufgabe der alten Landkarte ... und die Legitimität (oder Rechtfertigung) der Macht, ihre Herrschaft wiederaufzubauen“. Es scheint, dass die Verantwortung für die Realisierung dessen unweigerlich auf den Schultern jener liegt, die zur Generation Bruder Shenzhis gehören und noch am Leben sind; insbesondere jedoch liegt sie auf den Schultern der jungen Leute, die sich für das Land einsetzen. ${ }^{457}$

455 Eigene Übersetzung. Original siehe Dai 2009, S. 72.

456 Eigene Übersetzung. Original siehe ebd., S. $73 \mathrm{f}$.

457 Eigene Übersetzung. Original siehe ebd., S. 74 f. 
Die Erinnerung an Li Shenzhi wird im Jahr 2013 darüber hinaus jedoch auch durch eine posthume Veröffentlichung seiner eigenen historischen Dokumente aus den frühen 1960er Jahren, die einen wichtigen Beitrag zum historischen Verständnis der Kampagne gegen Rechtsabweichler leisten, aufrechterhalten. Genauer gesagt handelt es sich um eine Reihe von Selbstkritiken Lis, mit denen er um seine Rehabilitierung kämpfte, indem er in ihnen immer wieder seine Treue zur Partei und zum Sozialismus beteuert, einräumt, Fehler gemacht zu haben, und versichert, dass er bereit zur vollumfänglichen Transformation sei. ${ }^{458}$

Einige Autorinnen und Autoren der Kurzmemoiren in Yanhuang Chunqiu stehen jedoch in noch engerer Verbindung zu dem Opfer, dem sie durch die Veröffentlichung des Textes gedenken, als Dai Huang zu Li Shenzhi. In der Oktoberausgabe des Jahres 2008 erinnert beispielsweise die Autorin Jiang Yanyan 蒋 燕燕 an ihre wenige Monate zuvor verstorbene Mutter Zheng Defang 郑德芳, die ebenfalls eine Weggefährtin Li Shenzhis war und bis zur Kampagne gegen Rechtsabweichler stellvertretende Direktorin bei Xinhua gewesen ist. Dabei zeichnet Jiang den Weg der Mutter nach, der so typisch war für so viele Rechtsabweichler der Nachrichtenagentur Xinhua. Sie bezieht sich dabei sowohl auf ihre eigenen Erinnerungen als auch auf die Erinnerungen der Mutter, die diese vor ihrem Tod mit ihrer Tochter geteilt hatte, und betont, dass die Mutter jahrelang überhaupt nicht darüber sprechen konnte bzw. wollte, was ihr während ihrer Zeit im Laogai-System widerfahren ist. Zunächst betont sie, dass ihre Mutter unschuldig gewesen sei und wie so viele Rechtsabweichler der Partei und Mao eigentlich loyal gegenübergestanden und China auf einem sehr guten Weg gesehen habe. Dabei erörtert sie, wie ihre Mutter die damalige gesellschaftliche Stimmung in China nach der Rede Maos Über die richtige Behandlung der Widersprüche im Volk im Februar 1957 wahrgenommen habe: „Diese Rede erfreute nicht nur meine Mutter, sondern Menschen aus allen Gesellschaftsschichten des Landes glaub-

Dai Huang bezieht sich hier auf den von Li Shenzhi im Jahr 2000 veröffentlichten und danach noch mehrmals überarbeiteten Essay 50 Jahre Wind und Regen, welcher in der Zeitschrift Pekinger Frühling erschienen ist. In diesem reflektiert er die ,Jahre des Terrors“ zwischen 1949 und 1976. Insbesondere formuliert er in diesem eine umfassende Reflexion der Kulturrevolution. Demnach könne die historische Aufarbeitung der Kulturrevolution einen wichtigen Schritt für die Überwindung des Autoritarismus darstellen. Er formuliert außerdem Kritik an Deng Xiaoping und Jiang Zemin. Letzteren fordert er durch den Essay auf, politische Reformen hin zu mehr Demokratie durchzusetzen. Die in diesem Essay formulierten politischen Ideen gingen über den von der Partei noch tolerierten Rahmen hinaus und konnten deshalb nur außerhalb Chinas veröffentlicht werden. Dennoch drang der Text durch unterschiedliche Kanäle in intellektuelle Kreise innerhalb Chinas vor. Siehe Li 2000, http://beijingspring.com/bj2/2000/240/2003820193618.htm.

458 Siehe Li 2013b. 
ten, dass nun eine Ära der Demokratie und des Lichts kommen würde.“459 Eine missdeutete Aussage der Mutter während der Hundert-Blumen-Bewegung, bei der sie den Begriff „Menschenrechte“ habe fallen lassen, habe letztlich ausgereicht, um als Rechtsabweichlerin verurteilt zu werden. Daraufhin verbrachte sie ab dem Sommer 1957 fünf Jahre im Laogai-System, wurde zwischendurch entlassen und während der Kulturrevolution im Jahr 1968 aufgrund ihrer angeblich reaktionären Haltung erneut verurteilt, weswegen sie weitere fünf Jahre durch Arbeit umerzogen wurde. Hier geht die Beschreibung der Vergangenheit mit einer Aufarbeitung der eigenen Schuldgefühle der Autorin einher, die so typisch für viele Kinder ehemaliger Rechtsabweichler sind. Sie bezieht sich nun auf ihre eigenen Erinnerungen und berichtet, dass sie sich, als ihre Mutter im Jahr 1962 aus dem Arbeitslager zurückkehrte, sehr für sie geschämt habe, da diese ein schlechtes Licht auf sie selbst geworfen habe. Dies habe sich während der Kulturrevolution noch weiter verstärkt und dazu geführt, dass Jiang, als ihre Mutter ein zweites Mal zur Umerziehung durch Arbeit verurteilt wurde, den Kontakt zu ihr abgebrochen und ihn erst nach der Korrektur ihres Urteils wieder aufgenommen habe. Sie beschreibt die Zwickmühle, in der sich die Kinder der Rechtsabweichler damals häufig befanden, denn um die Liebe zur Revolution und zu Mao glaubhaft nach außen hin zu vermitteln, und damit nicht ausgeschlossen zu werden, sagten sich viele von ihren Eltern los, wenn sie einen schlechten politischen Status besaßen. Die Folgen waren sehr oft nicht nur eine Entfremdung zwischen Eltern und Kindern, sondern häufig auch über Jahrzehnte anhaltende quälende Schuldgefühle der Kinder den Eltern gegenüber. Dies wird auch in diesem Beitrag sehr deutlich.

$\mathrm{Zu}$ guter Letzt geht auch dieser Beitrag mit einer politischen Botschaft einher, indem Jiang darauf hinweist, dass ihre Mutter nach dem Beginn der Reform- und Öffnungspolitik einen „unbeugsamen Geist der Freiheit“ entwickelt habe. Und so können auch die Schlussworte der Autorin als versteckter Apell für die Freiheit gedeutet werden:

Mama ist gegangen, mit ihrer unnachgiebigen und freien Seele ist sie dorthin gegangen, wo sie frei denken, frei reden und in Freiheit agieren kann, und sie wird nicht gezwungen, irgendwohin zu gehen, es gibt alles, was sie möchte: keine Autoritäten, keine leeren Reden, echte Demokratie und Freiheit, unabhängig und gleich. Wo ist dieser Ort? Direkt am Meer, wo die Sonne aufgeht und der Erde ein Licht für alle menschlichen Spezies spendet. Dort kämpfen die Menschen gegen die Dunkelheit und den Sturm; die Menschen nutzen abertausende Jahre, um dort diesen Kampf zu finden, wo sie immer nur in eine Richtung gehen, an den Ort, an dem sie nichts anderes als Hoffnung sehen können - am Horizont. ${ }^{460}$

459 Eigene Übersetzung. Original siehe Jiang 2008, S. 62.

460 Eigene Übersetzung. Original siehe ebd., S. 65. 
Eine der wichtigsten Forderungen, die in einer Reihe von Artikeln in Yanhuang Chunqiu auch im Zusammenhang mit der Neudeutung der Kampagne gegen Rechtsabweichler immer wieder auftaucht, ist jedoch die nach einer staatlichen Aufarbeitung der Geschichte. Auch diese wird hauptsächlich von ehemals hochrangigen Parteikadern hervorgebracht. Im Februar 2010 etwa veröffentlichte Guo Daohui 郭道晖, ${ }^{461}$ Jurist und ehemaliges Mitglied des Rechtsausschusses des Nationalen Volkskongresses, einen Artikel, in dem er offen für eine staatliche Aufarbeitung der „historischen Fehler“ der Partei und eine wahrheitsgetreue Darstellung der Geschichte aufruft.

Er zieht dabei einen Vergleich mit anderen Ländern, die es geschafft haben, ihre schmerzhafte Vergangenheit aufzuarbeiten und sich für das Leid, das sie angerichtet haben, zu entschuldigen. Er verweist etwa auf die Aufarbeitung des Weißen Terrors (baise kongbu 白色恐怖) in Taiwan durch die GMD ${ }^{462}$ oder auf die Aufarbeitung des Nationalsozialismus in Deutschland und den Kniefall des Bundeskanzlers Willy Brandt, durch den er in Warschau im Jahr 1970 um Vergebung für die deutschen Verbrechen während des Zweiten Weltkriegs bat. Ein wichtiger Bestandteil der Aufarbeitung sei auch das Schaffen von Erinnerungsorten, die einen wichtigen Beitrag dazu leisten, dass eine Gesellschaft aus den Fehlern der Vergangenheit lernt, wie man anhand Deutschlands und Taiwans sehen könne.

Das Lernen aus der Geschichte hält Guo insgesamt für unerlässlich, um einen gesellschaftlichen Fortschritt zu erlangen, und deshalb fordert er dies auch für China ein:

Die staatlichen Verbrechen wurden durch die nationalen Führer am Volk begangen und diese entschuldigten sich aus politischen Gründen bei den Opfern; es ist förderlich, die Seelen der Verletzten zu beruhigen, ein Gefühl der sozialen Gerechtigkeit zu entwickeln, öffentliche und soziale Missstände und Widersprüche zu beseitigen und eine gesellschaftliche Versöhnung zu fördern. Dies ist in zivilisierten Ländern zu einer politischen und ethischen Praxis geworden. Ein weiteres fundamentales Ziel sollte es sein, die Staats- und Regierungschefs zu ermuntern, die politischen und ökonomischen Wurzeln zu reflektieren, die Schaden angerichtet haben, aus der Geschichte zu lernen, Systeme und spezifische institutionelle Probleme zu untersuchen und sie zu reformieren. Darüber hinaus sollten sie den Mut haben zu erkennen, dass das Übernehmen von politischer Verantwortung ihnen nicht schadet, sondern das Ansehen der Staats- und Regierungschefs erhöht. Willy Brandts

461 Guo Daohui trat 1948 der KPCh bei. Er ist einer der „drei Väter des chinesischen Rechts“. Zum Wirken Guo Daohuis siehe Xun 2017, http://news.163.com/17/1124/23/D420B8KJ0001875N. html.

462 Während des Weißen Terrors wurden ab dem Jahr 1947 Oppositionelle und Kritiker des Regimes gewaltsam und systematisch unterdrückt. Siehe Lin 2007. 
Entschuldigung hat ihm 1971 den Friedensnobelpreis eingebracht, was ein Beweis dafür ist. $^{463}$

Damit spricht er China gewissermaßen den Status eines zivilisierten Landes ab, indem er sehr deutlich anprangert, dass die „historischen Fehler“ im Allgemeinen und die Kampagne gegen Rechtsabweichler im Besonderen offiziell noch nicht in angemessener Art und Weise aufgearbeitet worden seien: „Leider haben die alten Machthaber in Chinas politischer Kultur diese Tradition vermissen lassen und keine Verantwortung und keinen Mut dafür aufgebracht. Die Menschen können schwerlich auf eine Entschuldigung oder eine Entschädigung durch die Behörden hoffen." 464 Denn auch wenn es, wie Guo anmerkt, seit dem Jahr 1978 durchaus positive Entwicklungen in China gegeben habe und die Machthaber es zuließen, dass über die Vergangenheit gesprochen wird, bedürfe es jedoch noch einer staatlichen Aufarbeitung, um in dieser Hinsicht mit Ländern gleichzuziehen, die das bereits getan haben.

In Bezug auf die Kampagne gegen Rechtsabweichler erwähnt Guo außerdem, dass diese nicht nur in Form einer angemessenen offiziellen Bewertung aufgearbeitet werden müsse, sondern, dass es darüber hinaus notwendig sei, den Opfern eine angemessene finanzielle Entschädigung zukommen zu lassen. Er deutet hier die Ungleichbehandlung zwischen den Opfern der Kampagne gegen Rechtsabweichler und denen der Kulturrevolution an. Hier zeigt sich erneut, dass die politische Entscheidung des Jahres 1978, die Rechtsabweichler anders zu „rehabilitieren“ und zu entschädigen als die Opfer der Kulturrevolution, immer wieder auch die inoffizielle Geschichtsschreibung und somit auch das kollektive Gedächtnis beeinflusst.

Zusammenfassend lässt sich festhalten, dass ein Großteil der Artikel zur Kampagne gegen Rechtsabweichler, ebenso wie zu anderen „historischen Fehlern“ der KPCh, die offizielle Geschichtsschreibung herausfordert, wobei sie sich häufig auf Erinnerungen von Zeitzeugen bzw. ihrer Angehörigen beziehen. Die Kampagne wird, im Gegensatz zur Resolution von 1981, eindeutig als „historischer Fehler“ eingeordnet. Im Gegensatz zur offiziellen Geschichtsschreibung räumen die Autoren also nicht ein, dass sie, obwohl Fehler gemacht worden seien, zum Schutz der Partei dennoch richtig und notwendig gewesen sei. Neben den erkennbaren Intentionen der Autoren, gegen das Vergessen der Opfer anzuschreiben oder ihr eigenes Trauma aufzuarbeiten, ist die Geschichtsschreibung in Yanhuang Chunqiu davon geprägt, dass sie vor allem mit Forderungen nach po-

463 Eigene Übersetzung. Original siehe Guo 2010, S. $41 \mathrm{f}$.

464 Eigene Übersetzung. Original siehe ebd., S. 42. 
litischen Reformen verbunden ist. Und dennoch blieb die Zeitschrift für sehr lange Zeit weitgehend von der staatlichen Zensur verschont bzw. erhielt sie weiterhin eine offizielle Publikationslizenz. Als Grund hierfür kann die Tatsache angesehen werden, dass die Autoren in ihren Artikeln teilweise zwar sehr deutlich Kritik an der Partei üben, ihre Herrschaftslegitimation jedoch nicht grundsätzlich in Frage stellen. Anders ausgedrückt, äußert eine Reihe von Autoren zwar ihre Unzufriedenheit mit der (Geschichtspolitik der) Partei, dies bedeutet jedoch keineswegs, dass diese Äußerungen als Aufruf zum Sturz der Partei gelesen werden können. Vielmehr argumentieren die Autorinnen und Autoren sehr häufig im Geiste der Demokratiemauerbewegung und wollen einen Wandel in China anstoßen, der mit der KPCh stattfindet und nicht ohne sie. Und deshalb agierten sie sehr lange innerhalb der Grenzen des Sagbaren.

Dass sich diese Grenzen des Sagbaren jedoch auch verschieben können, wurde sowohl nach den Studierendenprotesten 1989, als auch im Zuge der Machtübernahme Xi Jinpings deutlich. Dies zeigt sich insbesondere am Fall der nach so vielen Jahren plötzlich schwindenden Toleranz der staatlichen Behörden gegenüber Yanhuang Chunqiu, deren Herausforderung der offiziellen Geschichtsschreibung nach dem Beginn des Kampfes gegen den historischen Nihilismus und der damit verbundenen Vorgabe, dass über die „historischen Fehler“ der Partei fortan nicht mehr gesprochen werden darf, nicht mehr toleriert werden konnte - zu eng ist die Legitimität der Herrschaft Xis mit der der wichtigsten Machthaber der modernen chinesischen Geschichte Mao Zedong und Deng Xiaoping verknüpft. Eine Weiterführung des Diskurses über die „historischen Fehler“ der Partei, wie er in Yanhuang Chunqiu so viele Jahre geführt wurde, würde fortan eine zu starke Gefahr für seinen Machterhalt darstellen. Auch die Tatsache, dass die Herausforderung der offiziellen Narrative durch die Zeitschrift im Wesentlichen aus dem Inneren der Partei heraus erfolgte, auch wenn die Autorinnen und Autoren der Artikel zum Zeitpunkt des Erscheinens kein hohes politisches Amt mehr innehatten, dürfte der neuen politischen Führung Chinas um Xi Jinping ein Dorn im Auge gewesen sein. Denn dies kann nicht gerade als sichtbares Zeichen der Einheit der Partei angesehen werden - eine der wichtigsten politischen Agenden Xis.

\subsection{Reportageliteratur als alternative Erinnerungsorte}

Ein weiteres wichtiges Genre innerhalb der inoffiziellen Geschichtsschreibung zur hier diskutierten Kampagne gegen Rechtsabweichler stellt das der Reportageliteratur (baogao wenxue 报告文学) dar. Es hatte sich bereits in den 1920er Jahren herausgebildet und dient seitdem, mit Ausnahme der Jahre der Kulturrevolution, 
im Wesentlichen der kritischen Betrachtung gesellschaftlicher Vorgänge. Insbesondere seit der Reform- und Öffnungspolitik „wurde sie zum Forum der Diskussion sensibler und in der politischen Diskussion zunächst tabuisierter Themen bei der Bewältigung der jüngsten Vergangenheit und dringender aktueller Probleme der Zeit“..465 Die Reportageliteratur stellt somit auch ein geeignetes, wenn auch politisch nicht immer gänzlich unproblematisches Mittel dar, alternative Narrative zur Kampagne gegen Rechtsabweichler zu entwerfen. Insbesondere ab den frühen 2000er Jahren wurde sie jedoch ein wichtiger Bestandteil im Kampf um das kollektive Gedächtnis.

\subsubsection{Die Rechtsabweichler von Jiabiangou (Yang Xianhui)}

Der Schriftsteller Yang Xianhui 杨显惠 (geb. 1947), der ebenso wie Hu Ping zur Rotgardistengeneration gehört, begann in den späten 1990er Jahren damit, durch sein literarisches Schaffen eine alternative Geschichtsschreibung $\mathrm{zu}$ betreiben und sich intensiv mit dem Schicksal der Opfer der Kampagne gegen Rechtsabweichler auseinanderzusetzen. Auch wenn er nicht durch die Kampagne selbst betroffen gewesen ist, etwa weil einer seiner engen Angehörigen als Rechtsabweichler verurteilt worden wäre, und er deshalb in seiner Jugend auch keine Diskriminierungen erdulden musste, kam er ab Mitte der 1960er Jahre erstmals mit Rechtsabweichlern in Berührung. Yang arbeitete damals als einer der vielen Millionen gebildeten Jugendlichen auf dem Land, wo er bei seiner täglichen Arbeit auch einigen Rechtsabweichlern begegnete. Wie er später zu Protokoll gab, habe ihn ihr Schicksal so sehr berührt, dass er schon damals mehr darüber erfahren wollte, was aufgrund der Kulturrevolution jedoch kaum möglich gewesen sei. Damals hörte er erstmals auch von dem Umerziehungslager Jiabiangou 夹边沟, in dem zwischen den Jahren 1957 und 1961 etwa 3.000 Intellektuelle durch Arbeit umerzogen worden sind. ${ }^{466}$ Etwa 2.500 von ihnen sollen dabei ihr Leben verloren haben. Die Frage nach dem Schicksal der ehemaligen Insassen sollte ihn auch viele Jahre später nicht mehr loslassen und so begann er im Jahr 1997, rund um den 40. Jahrestag des Ausbruchs der Kampagne, mit den Recherchen zur Geschichte des Lagers und dem Schicksal der Opfer. Da ihm der Zugang zu Archivmaterial weitgehend verwehrt geblieben ist, interviewte er in den folgenden

465 Müller 2004b, S. 258.

466 Das Arbeitslager befand sich in der Wüste der nordwestlichen Provinz Gansu 甘肃. Es wurde aufgrund der immer schlechter werdenden Bedingungen und der Vielzahl der Todesfälle im Oktober 1961 von den chinesischen Behörden geschlossen. Siehe Seymour und Anderson 2015, S. $175 \mathrm{ff}$. 
drei Jahren hierzu rund 100 ehemalige Rechtsabweichler und ihre Familien. Dabei profitierte er auch von den zu jener Zeit relativ großen intellektuellen Freiheiten. ${ }^{467}$

Er nutzte die Gunst der Stunde und veröffentlichte bereits im Jahr 2000 die Erzählung Die Frau aus Shanghai (Shanghai nüren 上海女人) in der Zeitschrift Shanghaier Literatur (Shanghai wenxue 上海文学). In den darauffolgenden Jahren veröffentlichte Yang Xianhui dann weitere Geschichten ehemaliger Insassen aus Jiabiangou. Diese wurden im Jahr 2003 schließlich unter dem Titel Geschichten aus Jiabiangou (gaobie jiabiangou 告别夹边沟) vom Shanghaier Kunst- und Literaturverlag (Shanghai wenyi chuban she 上海文艺出版社) herausgegeben. ${ }^{468}$ Allerdings mussten Yang und der Verlag zu einer List greifen, um die Zensur zu umgehen - trotz der relativ großen intellektuellen Freiheiten handelte es sich schließlich immer noch um ein hochsensibles Thema, welches in der Öffentlichkeit bis dato kaum diskutiert worden war. ${ }^{469}$ Obwohl die Erzählungen Yangs zum Genre der Reportageliteratur gezählt werden können, veröffentlichte der Verlag das Buch in der Rubrik „fiktionale Literatur“ (xiaoshuo 小说), außerdem schrieb Yang die Geschichten größtenteils im Erzählstil und fügte ihnen fiktionale Elemente hinzu. Deshalb können diese Erzählungen auch als Reportageromane (xinwenti xiaoshuo 新闻体小说) bezeichnet werden. Ein weiterer Grund, warum Autor und Verlag die Zensur umgehen konnten, liegt möglicherweise darin, dass sich die Erzählungen auf die Jahre 1957 bis 1961 beschränken und eine Verknüpfung mit dem China der Veröffentlichungszeit vermieden wird. Das heißt, die Tatsache, dass es auch im China der Jahrtausendwende noch Arbeitslager gegeben hat, bleibt in den Erzählungen aus Jiabiangou unerwähnt. Die Geschichten der ehemaligen Rechtsabweichler stoßen in jenen Jahren auf großes öffentliches Interesse und Yang gewann im Jahr 2003 sogar den Preis Beste Kurzgeschichte, der jährlich von der Chinesischen Vereinigung für Kurzgeschichten verliehen wird. ${ }^{470}$ Sebastian Veg sieht in der Veröffentlichung der Erzählsammlung im Jahr 2003 einen Wendepunkt im öffentlichen Diskurs um die Kampagne

467 Yang 2009, S. $7 \mathrm{ff}$.

468 Die Erzählungen wurden später auch ins Englische und ins Deutsche übersetzt. Die folgende Analyse bezieht sich auf die im Jahr 2009 erschienene deutsche Erzählsammlung Die Rechtsabweichler von Jiabiangou.

469 Die Erzählsammlung durfte lediglich zwischen den Jahren 2005 und 2008 nicht mehr nachgedruckt werden. In dieser Zeit war das Buch jedoch auf dem Schwarzmarkt erhältlich. Nach dem Jahr 2008 konnte es zunächst wieder regulär erworben werden. Veg 2014, S. 519.

Gegenwärtig kann es jedoch erneut nicht mehr in chinesischen Buchhandlungen erworben werden.

470 Yang 2009, S. 14. 
gegen Rechtsabweichler. Bisherige Abhandlungen zu dem Thema wurden zuvor meist zensiert und konnten deshalb nicht innerhalb Chinas veröffentlicht werden oder stießen nicht auf ein breites öffentliches Interesse. Außerdem beschränkten sie sich zuvor meist auf Memoiren ehemaliger Rechtsabweichler. Großes Interesse bestand in jenen Jahren eher an (inoffiziellen) Veröffentlichungen zur Kulturrevolution, sodass die Ereignisse der Jahre 1957 und 1958 nur langsam zum Teil der politischen Debatte durch zivilgesellschaftliche Akteure geworden sind. ${ }^{471}$

In Yangs Erzählungen liegt der Fokus vor allem auf dem Schicksal der Rechtsabweichler während der Umerziehung durch Arbeit im sogenannten Laogai-System, weswegen sie auch der Gefängnisliteratur zugeordnet werden können. Da sie im Wesentlichen auf Interviews mit Zeitzeugen beruhen, nimmt das individuelle Gedächtnis eine zentrale Funktion in der Neudeutung der Geschichte ein. Der Autor wollte die Kampagne gegen Rechtsabweichler ins öffentliche Bewusstsein rücken, sodass sich Ereignisse wie diese in Zukunft nicht noch einmal wiederholen. Außerdem nimmt die Erzählsammlung, wie viele andere inoffizielle Veröffentlichungen zu diesem Thema auch, eine Funktion als eine Art alternativer Erinnerungsort für die verstorbenen Opfer der Kampagne ein:

Heutzutage wissen nur wenige Menschen etwas über die Geschichte. Viele der Überlebenden sind inzwischen entweder verstorben oder schweigen. Die Täter vertuschen das Geschehen weiter. Ich möchte, dass die Menschen die Wahrheit erfahren und den Schmerz derer nachfühlen, die ihn erlebt haben. Deshalb habe ich mich so sehr darum bemüht, dieses dunkle Kapitel ans Licht zu bringen und die Öffentlichkeit an den Lebensgeschichten teilhaben zu lassen, die ich entdeckt habe. Ich hoffe, dass sich so eine Tragödie nie wiederholen wird. Noch wichtiger aber war es mir, mit diesem Buch für die, die in der entlegenen Wüste begraben liegen, dieses Kapitel in ihrem Leben zu einem Abschluss zu bringen. ${ }^{472}$

Thematisch umfassen die Erzählungen die empfundene Ungerechtigkeit der Verurteilung als Rechtsabweichler und das damit häufig verbundene Gefühl der Betroffenen, in eine Falle gelockt worden zu sein, den Überlebenskampf im Arbeitslager an sich, der insbesondere durch die Hungersnot im Zuge des Großen Sprungs verschärft worden ist, die häufig anhaltende Loyalität der Opfer zur Partei, den Verlust der menschlichen Würde sowie den Abschied aus Jiabiangou, als das Lager geschlossen worden ist. Jede Geschichte beschäftigt sich mit den Einzelschicksalen innerhalb eines beschränkten Personenkreises und wird aus der Perspektive eines Rechtsabweichlers erzählt.

Das zentrale Thema der Erzählungen ist jedoch das des Hungers, dem die Rechtsabweichler in Lagern wie Jiabiangou ausgesetzt gewesen sind, und der

471 Veg 2014, S. 516.

472 Yang 2009, S. 15. 
damit in Zusammenhang stehende Überlebenskampf. Dieser ist nicht nur durch die Schäden des Großen Sprungs enorm verschärft worden, sondern auch durch die Tatsache, dass die Regierung das Lager sich selbst überlassen und es nicht mit Lebensmitteln unterstützt hatte. ${ }^{473}$ Bereits bevor die Große Chinesische Hungersnot 1958-61 (sannian de jihuang 三年的饥荒) ihren Höhepunkt erreicht hatte, war die Versorgungslage in Jiabiangou sehr schlecht gewesen, wie in der Geschichte Der Dieb dargestellt wird, die von dem Schicksal des Rechtsabweichlers Yu Zhaoyuan erzählt:

\begin{abstract}
Damals bekam jeder Rechtsabweichler ein dreiviertel Pfund Getreide pro Tag, das war unter normalen Bedingungen ausreichend. Aber die Rechtsabweichler arbeiteten zehn, manchmal sogar sechzehn Stunden am Tag. Die schwere, ungewohnte Arbeit zehrte ihre Körper völlig aus. Weniger als ein Pfund Getreide konnte ihren Energiebedarf nicht decken, und viele Rechtsabweichler verhungerten. ${ }^{474}$
\end{abstract}

Diese ohnehin schon dramatische Situation verschlechterte sich demnach ab dem Jahr 1960 zusehends, sodass die Zahl der Hungertoten täglich stieg. Teilweise greifen die Erzählungen inhaltlich auch direkt ineinander über. Die Geschichte Hass auf den Mond, die ebenfalls von der großen Hungersnot der Insassen berichtet, wird aus der Perspektive Xi Zongxiangs, eines direkten Bekannten Yu Zhaoyuans, erzählt. Der von Yang gewählte Erzählstil ermöglicht dabei teilweise eine sehr deutliche Darstellung der schrecklichen Verhältnisse, in denen die Rechtsabweichler in jenen Jahren lebten:

Viel schlimmer war allerdings, dass bereits bis zu einem Drittel der verlegten Rechtsabweichler verhungert war. Überall im Wüstengebiet entlang der Gräben und am Deich waren frische Gräber. Die Rechtsabweichler, die noch am Leben waren, befanden sich in einem schlimmen Zustand. Die Hälfte von ihnen war bettlägerig. Diejenigen, die sich noch bewegen konnten, lagen oder saßen zur Mittagszeit vor ihren Höhlen in der Sonne. Viele hatten nicht mehr die Kraft, in der Küche ihr Essen zu holen. Also gingen die Köche zur Essenszeit mit einem Kübel herum und gaben die Mahlzeiten aus. Sie füllten jedem eine halbe Kelle Brei in das mit zittrigen Händen gehaltene Geschirr. Die Tagesration war ein halbes Pfund Bohnenmehl. [...] Die meisten Rechtsabweichler warteten ruhig auf ihren Tod. Nur einige, die ihr Schicksal nicht akzeptieren wollten, suchten ihr Heil in der Flucht. ${ }^{475}$

Yang lässt jedoch immer wieder Formulierungen einfließen, die den Erzählstil aufbrechen und daran erinnern, dass es sich um eine Reportage im Deckmantel einer Erzählung handelt: „Wenn man seinen Lebenswillen nicht aufgibt, dann

473 Ebd., S. 8.

474 Ebd., S. 57.

475 Ebd., S. 71. 
gibt es auch in ausweglosen Situationen Hilfe. Das sagte Yu Zhaoyuan später in einem Interview zu mir. “476 Reportage- und Erzählstil wechseln sich innerhalb der einzelnen Geschichten häufig miteinander ab.

Ein weiteres zentrales Thema, welches einen wichtigen Stellenwert in den Erzählungen der ehemaligen Rechtsabweichler einnimmt, ist das des moralischen Verfalls, welcher während der Hungersnot durch den Kampf um das nackte Überleben zunehmend verstärkt worden ist. $\mathrm{Zu}$ den Überlebensstrategien Yu Zhaoyuans etwa gehörte der Diebstahl von Lebensmitteln, auch wenn er bis dahin noch nie etwas gestohlen hatte, wie er beteuert. Doch als mehrere seiner Mitinsassen vor seinen Augen verhungert seien, sei sein Leben einzig und allein von der Frage „Wie kann ich überleben?““77 geprägt gewesen. Auch Xi Zongxiang vergisst im Kampf gegen den Hungertod seine Moralvorstellungen und ist sogar bereit, eine Straftat zu begehen, um in ein Gefängnis verlegt zu werden, von dem er gehört hatte, dass die dortigen Insassen nicht verhungern müssten. Letztlich entschließt er sich deshalb, zunächst ein Schwein und dann ein Schaf zu stehlen und zu schlachten. Die erhoffte Strafe bleibt jedoch aus, da einige seiner Mitinsassen ihm dabei „helfen“, die Tat zu vertuschen. Letztlich führen die lebensbedrohlichen Umstände dazu, dass der Verlust der Moral durch den Akteur Xi Zongxiang selbst eine Akzeptanz erfährt:

Da besann ich mich mit einem Mal anders: Ich wollte absichtlich eine Straftat begehen, um ins Gefängnis zu kommen. Aber nichts passierte, ganz im Gegenteil, ich hatte mir den Bauch vollgeschlagen. Den Mutigen gehört die Welt, die Feigen verhungern! Dann sollte es eben so sein, und ich würde in Jiabiangou bleiben. Wenn ich irgendwo etwas stehlen könnte, würde ich es stehlen, wenn ich irgendetwas zu essen fände, würde ich es essen. So hätte ich ein Auskommen. Vielleicht wäre bald alles vorbei, und die Rechtsabweichler würden nach Hause geschickt. Dann wäre ich als Insasse eines Umerziehungslagers besser dran als in einem Straflager. ${ }^{478}$

Im Zusammenhang mit dem Kampf gegen den Hunger arbeitet Yang Xianhui neben dem moralischen Verfall den schleichend eintretenden Verlust der menschlichen Würde der Rechtsabweichler und ihrer damit verbundenen Demütigung heraus. In der Erzählung Satt, die auf den Erinnerungen des ehemaligen Rechtsabweichlers Gao Jiyi beruht, wird auch von dem Schicksal seines viel älteren, damaligen Kameraden Niu Tande berichtet. Im Frühjahr des Jahres 1960 unterstützt er Gao in den Stunden seiner größten Not, als er sehr krank ist, indem er seine Kleidung wäscht und Gaos Erbrochenes beseitigt. Eines Tages erwischt er

476 Ebd., S. $79 f$.

477 Ebd., S. 51.

478 Ebd., S. 105 f. 
Niu zufällig dabei, wie er heimlich eine getrocknete Masse verspeist. Schnell erkennt er, dass es sich bei dieser Masse um eine Mischung aus seinen Fäkalien und seinem Erbrochenen handelt. Diese Selbstdemütigung seines älteren Kameraden habe einen Schock und eine große Trauer in ihm ausgelöst: „Plötzlich überkam mich eine große Trauer: Ein zuvorkommender, respektierter, alter Ingenieur aß plötzlich das, was jemand ausgebrochen oder ausgeschieden hatte. Wie konnte er sich selbst so demütigen?“479 Im Interview mit Yang gibt er zu Protokoll, dass ihn diese Geschichte nicht mehr losgelassen und er bisher noch nie darüber gesprochen habe.

Die durch den Hunger ausgelösten Demütigungen werden auch in der Erzählung Die Frau aus Shanghai dargestellt. Hier erinnert sich der ehemalige Rechtsabweichler Li Wenhan daran, dass sie Grassamen, Mäuse, Regenwürmer oder Eidechsen aßen, um ihr Überleben zu sichern. Die drastische Darstellung dessen, wozu die Insassen Jiabiangous während der Großen Hungersnot im Stande waren, um sich dem Tod entgegenzustellen, wird in dieser Erzählung sogar noch gesteigert bis hin zur Entmenschlichung der Rechtsabweichler: Die Frau eines kürzlich verstorbenen Rechtsabweichlers kommt im Oktober 1959 in das Lager, um ihren Mann Dong Jianyi zu besuchen. Als sie von seinem Tod erfährt, möchte sie seinen Leichnam mitnehmen, doch er ist nicht richtig vergraben worden. Die Mitinsassen versuchen der Frau tagelang zu verheimlichen, wo sich der Leichnam Dongs befindet, denn er befindet sich nicht etwa in einem Grab, sondern er liegt tagelang offen in der Wüste, was dazu führt, dass dem Leichnam zunächst die Kleider gestohlen und schließlich sogar das Fleisch von den Knochen geschnitten wird. Li Wenhan stellt in der Erzählung fest, dass der Hunger die Menschen letztlich zu Tieren gemacht habe: „Ach, die Menschen sind alle zu Tieren geworden. Nicht mal ein Tiger wäre so unbarmherzig, sein Junges zu fressen. Menschen fressen Menschen. Sind das überhaupt noch Menschen?“480 Um ihrem verstorbenen Mann seine Würde zurückzugeben, beschließt seine Frau, seinen Leichnam $\mathrm{zu}$ verbrennen und die Asche und die verkohlten Überreste zurück in seine Heimat Shanghai zu bringen. Doch auch dies ist nicht ohne eine weitere Form der Demütigung möglich, denn das Feuer hatte nicht ausgereicht, um die Leiche vollständig in Asche zu verwandeln, und so versucht sie zunächst die restlichen Knochen in einen Pullover zu wickeln. Sie sind jedoch so groß, dass sie herausragen, weswegen sie sich für den Transport von Li Wenhan eine Militärdecke leiht.

479 Ebd., S. 124.

480 Ebd., S. 194. 
Die Darstellungen des Schreckens, dem die Rechtsabweichler während ihrer Umerziehung durch Arbeit ausgesetzt waren, beschränken sich in den Erzählungen Yang Xianhuis fast nur auf die Darstellungen des Körperlichen, auf den Kampf gegen den Hunger, die dadurch ausgelösten Krankheiten und auf die schlechten Lebensbedingungen in den Unterkünften. Die ideologischen Aspekte der Haft werden hingegen fast gar nicht thematisiert. Das heißt, die im Zuge dessen durchgeführte Bildung, etwa durch ein Studium der Schriften Mao Zedongs, wird nur angedeutet, spielt aber in der Wiedergabe der Erinnerungen der Rechtsabweichler, auf die sich Yang Xianhui bezieht, so gut wie keine Rolle. ${ }^{481}$

Trotz des klaren Fokus Yang Xianhuis auf die Erinnerungen der ehemaligen Rechtsabweichler und ihren Überlebenskampf gaben einige in den Interviews zu Protokoll, dass sie trotz der Ungerechtigkeit und des Leids, die ihnen in jenen Jahren widerfahren sind, den Glauben an die Partei nicht verloren haben. Sie sahen dies damals eher als ein Irrtum an, der auf dem Weg der sozialistischen Entwicklung passieren könne, wie Li Wenhan beispielsweise berichtet:

\footnotetext{
Du fragst, warum wir nicht abgehauen sind? Einige haben ja die Flucht ergriffen. Cui Yi zum Beispiel, Zhong Yuliang und Wei Changhai auch, oder der Leiter der An- und Verkaufsgenossenschaft des Kreises Minqin. Aber das waren nur einzelne, die meisten blieben. Wir waren ja voller Illusionen. Wir dachten, eines Tages würde die Partei merken, dass wir zu Unrecht als Rechtsabweichler verurteilt worden waren. Sie würde sicher die Entscheidung korrigieren und uns rehabilitieren. Außerdem hielten wir die Erziehung durch Arbeit für eine Probe, auf die uns die Partei zur Überprüfung unserer Loyalität gestellt hatte. Wenn wir wegliefen, dann würden wir sie betrügen. Das wäre dann ein Verrat an der gesamten Revolution. Einmal gefehlt, tausendmal bereut - davor hatten wir Angst. Deshalb flohen nur wenige. $^{482}$
}

Trotz der sehr kritischen Darstellung der Lebensumstände der Insassen des Lagers ist der Zusammenhalt zwischen den Insassen gleichfalls ein wichtiges Thema, welches der in den Geschichten beschriebenen Entmenschlichung der Insassen etwas entgegenzusetzen scheint bzw. einen relativierenden Charakter bezüglich der Darstellungen des moralischen Verfalls aufweist. Denn so wird beispielsweise nicht aufgedeckt, dass es Xi Zongxiang war, der zunächst das Schwein und dann das Schaf schlachtet, weil sich seine Mitinsassen solidarisch gezeigt und geholfen hatten, die Tat zu vertuschen. Die menschliche Seite der Insassen wird auch dadurch betont, dass sich einige ehemalige Rechtsabweichler gemäß der Darstellungen Yangs erinnert haben wollen, dass sie stets mit anderen ihr Essen teilten bzw. andere ihnen von ihrem Essen etwas abgaben. Beispielsweise erinnert

481 Vgl. Veg 2014, S. 521 f.

482 Yang 2009, S. 175. 
sich Yu Zhaoyuan daran, wie er zwar Essen gestohlen, sein Diebesgut jedoch mit anderen geteilt habe, wofür ihm seine Mitinsassen sehr dankbar gewesen seien: „Lao Yu, wenn ich es zurück nach Lanzhou schaffe, dann habe ich es dir zu verdanken. Ich werde dich $\mathrm{zu}$ einer gebratenen Ente einladen. Allerdings schmeckt die nicht halb so gut wie diese Schafhaut. “483 Der körperliche Verfall und die damit verbundenen Demütigungen, so wird es dargestellt, habe die Insassen zum Teil noch stärker zusammengeschweißt. Im Interview mit Yang Xianhui erinnert sich Gao Jiyi im Jahr 1999, dass der Zusammenhalt zwischen ihm und Niu Tande noch stärker geworden sei, nachdem er ihn dabei erwischt hatte, wie er die getrocknete Masse aus Erbrochenem und Fäkalien aß:

Sie brachte uns noch enger zusammen. Ich war kein guter Schreiner, aber der Dienstälteste in der Schreinerbrigade von Jiabiangou. Man kannte mich, und es gelang mir immer, an etwas Essbares zu kommen. Wenn ich das Werkzeug der Gemüsebrigade reparierte, bekam ich dafür einige Rüben. Ich teilte sie mit Niu. Als ich in der Mühle arbeitete, stahl ich Mehl, um Brei zu machen, davon gab ich ihm auch etwas ab. Ich hatte in Jiabiangou außerdem eine spezielle Aufgabe. Es gab zwei große Öfen, um für die fast zweitausend Rechtsabweichler Essen zuzubereiten. Einer stand bei der Baubrigade, einer bei der Landwirtschaftsbrigade. Die Aufsätze für die Dampfbrötchen gingen ständig kaputt, entweder zerbrach das Holz, oder sie saßen nicht richtig auf dem Topf, und ich wurde zur Reparatur gerufen. Jedes Mal, wenn ich einen Aufsatz reparierte, kratzte ich die Essensreste heraus, die hängengeblieben waren. Oder ich steckte einfach ein paar gedämpfte Brötchen ein. Der Koch tat so, als würde er es nicht merken. Egal, was es war, ich teilte immer mit Niu Tande. ${ }^{484}$

Durch die Wiedergabe solcher Erinnerungen, die, trotz aller Schrecken jener Jahre, positive Aspekte wie Kameradschaft und Zusammenhalt betonen, legt Yang Xianhui dar, dass es keinen kompletten gesellschaftlichen moralischen Verfall gegeben zu haben scheint. Auch ein etwaiges Denunziantentum der Insassen untereinander spielt in der Darstellung der Schicksale der Rechtsabweichler durch Yang so gut wie keine Rolle. Dies stellt sich in einigen Memoiren ehemaliger Rechtsabweichler, insbesondere in jenen, die nur außerhalb Chinas veröffentlich werden konnten, häufig anders dar. In diesen wird der Kampf um Nahrung meist als ein sehr einsamer Kampf beschrieben, wonach es den Insassen in dieser Situation nicht in den Sinn gekommen wäre, das bisschen Nahrung, das sie auftreiben konnten, auch noch zu teilen. In diesen wird häufig auch beschrieben, dass Insassen sich gegenseitig denunzierten, wenn sie mitbekamen, dass sich ein anderer mit Diebesgut den Bauch vollgeschlagen hatte. Dies war häufig mit der Hoffnung verbunden, den niedrigen sozialen Status, den sie als Rechtsabweichler

483 Ebd., S. 75.

484 Ebd., S. 126. 
ohnehin besaßen, zumindest innerhalb des jeweiligen Arbeitslagers, ein wenig aufwerten zu können. ${ }^{485}$

Insgesamt fordert Yang Xianhui, trotz der teilweise sehr drastischen Darstellungen der Lebensumstände der Rechtsabweichler im Laogai-System, in seinen Erzählungen zwar die offizielle Geschichtsschreibung, nicht jedoch die Herrschaftslegitimation der KPCh heraus, was ebenfalls dazu beigetragen haben dürfte, dass die Erzählsammlung innerhalb Chinas veröffentlicht werden durfte. Die Auslöser der Hungersnot, das heißt die Fehler des Großen Sprungs nach vorn, bleiben weitgehend unerwähnt. Ebenso wird von der Willkür der Parteikader oder den Misshandlungen der Insassen durch diese nur andeutungsweise berichtet.

\subsubsection{Internes 1957: Altar des Leidens (Hu Ping)}

Hu Ping verließ China im Jahr 1987, um einige Jahre später an der Harvard-Universität promoviert zu werden. In dieser Zeit setzte er sich zunehmend für Menschenrechte in China ein. In den darauffolgenden Jahren begann er zudem eine alternative Geschichtsschreibung zu betreiben. Ein ausschlaggebender Faktor hierfür war neben seinen Erfahrungen während der Kulturrevolution die Tatsache, dass seine gesamte Jugend sehr stark von der Kampagne gegen Rechtsabweichler geprägt gewesen war. Sein Vater war im Jahr 1958, da war Hu gerade einmal neun Jahre alt, als Rechtsabweichler gebrandmarkt worden. Der damalige Professor der Jiangxi-Universität war von einem unzufriedenen Studenten fälschlicherweise als Rechter an den Pranger gestellt worden. Im Jahr 1994 beschreibt $\mathrm{Hu}$ Ping in einem Interview, was dies für ihn in den darauffolgenden Jahren bedeutet habe:

[...] because my grandparents and my uncles were landlords and my father was a "rightist", my class background was doubly "bad". Because of this, I always hated to fill out forms. I always felt embarrassed to say that my grandfather was a landlord, and my father was a "rightist". I had been ever distressed ever since my childhood. My whole self was divided into two halves. The first half was my deep love of my father. When he was a professor, his pay was two hundred yuan a month, but after he was labelled a "rightist", he only got one hundred yuan. With that amount of money he had to support eight people. ${ }^{486}$

485 Harry Wu berichtet beispielsweise davon, dass er in seiner Zeit im Arbeitslager eines Tages eine Gurke stahl. Als seine Mitinsassen dies rochen, denunzierten sie ihn beim Hauptmann. Weiterhin berichtet er, dass sich seine Mitinsassen daraufhin sogar daran beteiligten, ihn gemeinsam mit dem Hauptmann zur Strafe zu verprügeln. Wu 2009, S. 101.

486 Leung 1994, S. 56 f. 
Damit schildert er die Zerrissenheit, die die Kinder der Rechtsabweichler in den kommenden Jahren prägen würde, nämlich die Liebe $\mathrm{zu}$ ihren Eltern einerseits und der unbedingte Wille, Teil von Maos permanenter Revolution zu sein. Und so wurde $\mathrm{Hu}$ zu Beginn der Kulturrevolution aufgrund seines schlechten Klassenhintergrunds, wie so viele seiner Schicksalsgenossen zu jener Zeit, zunächst nicht bei den Roten Garden aufgenommen.

Während er sich in seinem Essay Über die Redefreiheit mit bestimmen historischen Ereignissen noch weitgehend in abstrakter Form auseinandergesetzt hatte, änderte sich dies in den darauffolgenden Arbeiten. Fast zeitgleich zur Veröffentlichung der Erzählsammlung Yang Xianhuis veröffentlichte $\mathrm{Hu}$ Ping im Jahr 2004 schließlich in China das Buch Internes 1957: Altar des Leidens (Chanji: 1957 kunan de jitan 禅机: 1957 苦难的祭坛). ${ }^{487}$ Die historische Reportage basiert, ebenso wie die Erzählungen Yangs, auf Interviews mit Zeitzeugen und seinen eigenen historischen Analysen. Das heißt, dass das individuelle Gedächtnis von Zeitzeugen hier ebenfalls eine zentrale Rolle für die Neudeutung der Geschichte spielt. Gleich zu Beginn des Buches erklärt Hu, dass er in diesem den Anspruch von wahren und detaillierten Aufzeichnungen erhebe. Dabei legt er jedoch nicht nur ein Zeugnis über die Geschichte ab, sondern verarbeitet auch seine eigenen Erfahrungen, die er als Angehöriger eines Rechtsabweichlers in den Jahren nach dem Ausbruch der Kampagne erdulden musste. Im Gegensatz zu Yang Xianhui verzichtet $\mathrm{Hu}$ jedoch auf das Hinzufügen vermeintlich fiktionaler Elemente.

Das Buch besteht aus 13 Teilen und insgesamt 54 Kapiteln, zuzüglich Vor- und Nachwort. Die Erklärungen zum Ausbruch der Kampagne bzw. die Darstellungen der historischen Ereignisse, die zu ihrem Ausbruch geführt haben, machen etwa ein Drittel des Buches aus, der zweite Teil stellt die Kampagne gegen Rechtsabweichler als solche dar. Der letzte Teil beschäftigt sich mit ihren Folgen und dem staatlichen Umgang mit den Opfern nach dem Tode Maos.

Bereits im Vorwort macht Hu Ping deutlich, dass er das Jahr 1957 als entscheidenden Wendepunkt der chinesischen Geschichte ansieht und die Kampagne gegen Rechtsabweichler in ihrer Bedeutung für China mit der Kulturrevolution gleichgesetzt werden könne. Ungewöhnlich für eine historische Reportage bedient er sich in seinen Ausführungen einer emotionalen und sehr metaphorischen Sprache. Deutlich wird dies zum Beispiel in dem Abschnitt, in dem er das Ausmaß der durch die Kampagne gegen Rechtsabweichler ausgelösten Katastrophe $\mathrm{zu}$ beschreiben versucht:

487 Das Buch wurde im chinesischen Verlag Guangdong Lüyou chubanshe 广东旅游出版社 veröffentlicht. Auch wenn das Buch zwischenzeitlich nicht mehr nachgedruckt werden durfte, konnte es im November 2017 regulär in der VR China erworben werden. Deshalb kann es der Geschichtsschreibung zugeordnet werden, die noch im von der Partei tolerierten Bereich liegt. 
Auch wenn die Bewegung vor dem Jahr 1957 nur in begrenzten Kategorien und Teilbereichen durchgeführt wurde, stellte das für die große Mehrheit der Menschen nur die aufziehenden Wolken eines weit entfernten Gewitters dar; die Menschen konnten die Bedeutung der Bewegung nicht wie die Zigeuner aus dem Kaffeesatz ablesen. Ab dem Jahr 1957 wurde die Bewegung wie ein riesiger Eisberg, aus dem Wasser traten Stücke davon hervor, welche ihre Ziele, Strategien und Methoden zu Tage treten ließen, sodass die Realitäten und Perspektiven unserer Nation und Generationen von Intellektuellen tief erschüttert wurden, nachdem sie von dem Erdbeben getroffen wurden und dies immer mehr Schüttelfrost auslöste ... ${ }^{488}$

Die von ihm gewählte Sprache deutet darauf hin, dass er durch sie nicht nur das Ausmaß der durch die Kampagne gegen Rechtsabweichler ausgelösten Katastrophe deutlich und bildhaft darzustellen versucht, sondern darüber hinaus auch, dass er dabei nicht ausschließlich die Perspektive eines objektiven Beobachters einnimmt und sich seine persönlichen Erfahrungen während und nach der Kampagne auch in seiner späteren Arbeit widerspiegeln. In diesem Zusammenhang betont er, dass es ihm ein inneres Bedürfnis gewesen sei, dieses Buch zu schreiben, und es deshalb strenggenommen keine typische Reportage und auch keine strenge akademische Arbeit darstelle. Er weist auch darauf hin, dass er keinen Zugang zu Archivmaterial gehabt habe, welches es ihm erlaubt hätte, ein großes Bild zur Kampagne gegen Rechtsabweichler zu entwerfen. Er erhebt dabei allerdings den Anspruch, ein wirklichkeitsgetreues Bild der Vergangenheit zu zeichnen: „Ich habe mein Bestes versucht, die Lüge wie einen Zahn zu entfernen. “489

In seiner historischen Betrachtung nimmt die Darstellung von Einzelschicksalen von Betroffenen einen hohen Stellenwert ein. Als er beispielsweise die Frage erörtert, ob die Hundert-Blumen-Bewegung eine Falle gewesen ist oder nicht, geht er ausführlich auf das Schicksal des damals zu Unrecht als Rechtsabweichler verurteilten ehemaligen Professors der Pekinger People's University of China Ge Peiqi 葛佩琦 ein. Sein Schicksal beschäftigte Hu Ping schon lange vor dem Erscheinen des Buches. Bereits im November 1992 hat er ein Interview mit ihm geführt, um mehr über seine Geschichte zu erfahren. ${ }^{490}$ Ge Peiqi war durch eine falsche Wiedergabe einiger öffentlicher Aussagen in den Strudel der Kampagne gegen Rechtsabweichler geraten. Am 24. Mai 1957 hielt er während eines Symposiums an der Universität vor Parteimitgliedern eine Rede. In dieser bemerkte er hypothetisch, dass, wenn es der Kommunistischen Partei nicht gelänge, dem Volk zu dienen, sie Gefahr liefe, gestürzt zu werden. Wenn die Partei gute Arbeit leiste,

488 Eigene Übersetzung. Original siehe Hu 2004, S. 2.

489 Eigene Übersetzung. Original siehe ebd., S. 9.

490 Ge Peiqi ist kurz darauf verstorben. Seine Memoiren wurden posthum im Jahr 1994 veröffentlicht. 
wäre alles gut, aber wenn ihr das nicht gelänge, könnten die Massen sie zu Fall bringen und Kommunisten töten. Diese Rede wurden dann drei Tage später bereits in leicht abgeänderter Form in der Zeitung der Universität veröffentlicht. Als Ge daraufhin den Vizepräsidenten der Universität Nie Zhen 聂真 aufsuchte, um die leicht fehlerhafte Wiedergabe seiner Rede korrigieren zu lassen, habe dieser ihm versichert, dass er sich keine Sorgen machen müsse, da die Partei auf der Suche nach Wahrheit auf der Grundlage von Fakten sei und Fehler deshalb auch jederzeit korrigiert werden könnten. Doch diese Korrektur sollte nicht mehr stattfinden und so erschien am 08. Juni 1957 ein Artikel in der Renmin Ribao mit dem Titel „Der Professor der People’s University of China Ge Peiqi veröffentlicht eine antikommunistische Rede“ (Renda jiaoshi Ge Peiqi fabiao fangong lanyun 人大教师葛佩琦发表反共言论), indem seine Worte noch stärker als zuvor aus dem Zusammenhang gerissen wiedergegeben wurden. In dem Artikel wurde ihm letztlich vorgeworfen, dass er zum Mord an Kommunisten aufgerufen habe. Seine Versuche einer Richtigstellung sollten erfolglos bleiben und so wurde er schließlich als Rechtsabweichler gebrandmarkt. Mit diesem Fall macht Hu Ping deutlich, wie schnell eigentlich treue Anhänger der Kommunistischen Partei ${ }^{491}$ in der Endphase der Hundert-Blumen-Bewegung zu Feinden erklärt werden konnten. ${ }^{492}$

Insgesamt vermeidet $\mathrm{Hu}$ Ping jedoch ein klares Urteil hinsichtlich der Frage, ob die Hundert-Blumen-Bewegung eine Falle gewesen ist oder nicht. In seiner Kritik an den Ereignissen jener Tage verfällt er wieder in eine blumige und metaphorische Sprache:

Schien die Sonne auf die Landschaft des sozialistischen Chinas? Oder sind die Schreie im Handumdrehen vom Angstschweiß der Kommandozentrale umhüllt worden? Oder war dies der unvorhergesehene Preis des Händlers, der wie ein großer Fisch mit den Garnelen, an der Börse mit kleineren und mittleren Privatanlegern spielt? Wenn sich die Bürger eines Landes nicht auf ehrliche Arbeit und freie Gedanken verlassen können, um ein stabiles politisches Leben zu erlangen, können sie sich nur noch auf die Mitteilungen verlassen, die ihnen innerhalb von wenigen Minuten übermittelt werden. Und dann muss dieses Land mit einer dunklen Wolke von Verschwörungen bedeckt sein. Wenn es schwer zu sagen ist, ob die Verschwörung auch eine „offene Verschwörung“ ist, ist der einzige Unterschied zwischen den beiden jener: Die Verschwörung lässt einen nervös und verlegen sein und sich rechts und links umsehen. ${ }^{493}$

491 Ge Peiqi hat während des Bürgerkriegs zeitweise als Geheimagent für die KPCh gearbeitet. Siehe Ge 1994, S. $25 \mathrm{ff}$.

$492 \mathrm{Hu} 2004$, S. $264 \mathrm{f}$.

493 Eigene Übersetzung. Original siehe ebd., S. 271. 
Insgesamt sieht er Vorfälle wie die der fälschlichen Verurteilung Ge Peiqis als Zeichen des moralischen Verfalls der damaligen chinesischen Gesellschaft:

\begin{abstract}
Aber in dem weiten Feld der „offenen Verschwörung“ werden wir Folgendes sehen: die opportunistische Psychologie, die Mentalität, dass sich der weise Mann nur um sein eigenes Versteck kümmert, das Einschlagen auf jemanden, der schon am Boden liegt, das Drehen der Fahne nach dem Wind und andere verabscheuungswürdigen Eigenschaften der Menschen, die wie Gift in ihr Blut eingedrungen sind und einen moralischen Verfall eines großen Teils des Landes verursacht haben.. .494
\end{abstract}

Ge Peiqis Fall weist einige Parallelen zu dem Schicksal von Hu Pings Vater auf. Dies ist möglicherweise ein Grund, warum er diesem in seinem Buch so viel Raum gibt.

Immer wieder bringt er zum Ausdruck, dass er die Kampagne und den Umgang mit den Intellektuellen für einen der schwerwiegendsten Fehler in der Geschichte der Volksrepublik China halte. Dabei wechselt sich eine blumige, metaphorische Sprache immer wieder mit sehr klar formulierten Aussagen zur Bewertung der Ereignisse jener Jahre ab. In einem Abschnitt, in dem seine Haltung zur Kampagne in besonderer Weise deutlich wird, arbeitet er beispielsweise zunächst mit einer metaphorischen, fast schon poetischen Umschreibung die Bedeutung des Wissens für die Menschheit heraus:

Seit dem Kampf gegen die Rechten, welcher die chinesischen Intellektuellen fest umschloss, konnten wir entdecken, dass dies eine Bewegung war, die das Wissen verschreckte. In der Geschichte der Menschheit verhält es sich mit dem Wissen folgendermaßen: Es ist der erste Stein, mit dem der Peking-Mensch in Zhoukoudian ${ }^{495}$ einst eine Flamme machte. Es ist der Apfel, der unter dem Blicke Newtons vom Zweig fiel. Es ist der Fußabdruck, den Marx' jahrelange tiefgreifende Arbeit unter einem Tisch in der Nationalbibliothek des Vereinigten Königreichs hinterlassen hat. Es ist der Doppeldecker aus einem Gestell aus Holz und von Leinen bedeckt, welches von den Gebrüdern Wright zu Beginn des 20. Jahrhunderts in aufregenden zwölf Sekunden und einer geringen Höhe von nur 2,5 Metern geflogen wurde ... Wenn wir sagen, dass die Geschichte der Menschheit die Realisierung alter Versuchungen ist, kann man auch die neuen Versuchungen wahrnehmen, welche ihre Geschichte erneut zu realisieren versuchen; oder aber sie ist wie eine aufgebrochene alte Fessel, die eine neue Fessel wahrnimmt und versucht die Geschichte aufzubrechen. Folglich ist das Wissen die unmittelbare und tiefgreifende Kraft, um diese Geschichte zu verändern..$^{496}$

494 Eigene Übersetzung. Original siehe ebd., S. 272.

495 Zhoukoudian周口店 ist ein Unterbezirk des Pekinger Stadtbezirks Fangshan房山区. Hier wurden in den 1920er Jahren bei Ausgrabungen Fossilien des rund 400.000 Jahre alten PekingMenschen entdeckt. Siehe Schmalzer 2008.

496 Eigene Übersetzung. Original siehe Hu 2004, S. 417. 
Hu schreibt dem Wissen hier eine ähnlich hohe Bedeutung wie der Redefreiheit in seinem Essay Ende der 1970er Jahre zu. Und deshalb könne es, wie auch ohne die Redefreiheit, ohne Wissen keine positive Entwicklung in China geben, denn: „Der Grad des Wissens identifiziert die Qualität einer Bevölkerung und einer Nation. “497 Er macht wiederholt deutlich, welch tiefgreifende Folgen der Umgang mit den Intellektuellen während der Kampagne gegen Rechtsabweichler für China hatte: „Eine Gesellschaft, in der Wissen und Intellektuelle Feinde sind, wird allmählich krank. “498

Erneut geht er darauf ein, warum die Kampagne eine so besondere Rolle in der Geschichte Chinas spielt. Auch hier nutzt er an einigen Stellen immer wieder kontrastreich eine sehr klare und wenig metaphorische Sprache. Zunächst analysiert er, dass die Kampagne gegen Rechtsabweichler eine neue Zeit in China eingeläutet habe. Sie unterscheide sich demnach insofern von vorherigen Kampagnen, als dass sie den Beginn des Populismus in der VR China bedeute und somit auch die Grundlagen für spätere Kampagnen gelegt habe: „Mit dem schnellen Start der Kampagne gegen Rechtsabweichler wurde ein überwältigender Trend im Land gebildet, denn wir können feststellen, dass dies eine Bewegung war, die den Populismus offiziell auf die Bühne Chinas gebracht hat. “499 $\mathrm{Hu}$ Ping betont, dass die Ereignisse ab dem Sommer 1957 die wahren Ideen der politischen Führung um Mao Zedong offengelegt hätten. Deng Xiaopings Rolle in der Kampagne bleibt zwar unerwähnt, jedoch merkt er an, dass auch andere Mitglieder des politischen Führungszirkels an dieser beteiligt gewesen seien, sodass diese Aussage durchaus auch als implizite Kritik an Deng bewertet werden kann.

Obwohl die Intellektuellen bereits während früherer Kampagnen in den 1950er Jahren zu Opfern geworden seien, bedeute die Bewegung gegen die Rechten nochmal einen neuen Umgang mit ihnen. Dabei betont er erneut die Verantwortung Mao Zedongs:

Die Veröffentlichung dieses Leitartikels ${ }^{500}$ bedeutete, dass sich Mao Zedong im Gegensatz zu früheren Kampagnen und Kämpfen dazu entschlossen hatte, ihren relativ engen Rahmen und das bisherige Ausmaß zu überschreiten, sodass chinesische Intellektuelle nun einen großen Prozess durch die Massen der Arbeiter, Bauern und Soldaten des Landes erdulden mussten. ${ }^{501}$

497 Eigene Übersetzung. Original siehe ebd., S. 418.

498 Eigene Übersetzung. Original siehe ebd., S. 420.

499 Eigene Übersetzung. Original siehe ebd., S. 420.

500 Gemeint ist hier die Veröffentlichung des Artikels Die Arbeiterklasse spricht am 09. Juli 1957 in der Renmin Ribao.

501 Eigene Übersetzung. Original siehe ebd., S. 421. 
Bei der Analyse der Ausweitung der Kampagne gegen Rechtsabweichler bezieht er sich jedoch nicht nur auf die politische Führungsriege Chinas, sondern er weist darauf hin, dass er davon ausgehe, dass der Kampf gegen die Rechten von einer Mehrheit der Bevölkerung unterstützt worden sei. Einen Grund dafür sieht er in der tiefen mentalen und sozialen Spaltung zwischen den Arbeitern und Bauern und den Intellektuellen in den 1950er Jahren. Er betont, dass diese dazu geführt habe, dass die Intellektuellen außerhalb ihrer eigenen sozialen Kreise kaum verstanden worden seien. ${ }^{502}$

Hu Ping legt dar, dass ein weiterer treibender Faktor für die Mobilisierung der Arbeiter und Bauern wirtschaftliche Ungleichheiten gewesen seien. Die Transformation des neuen Chinas war auch in der zweiten Hälfte der 1950er Jahre noch nicht so weit vorangeschritten, dass alle Ungleichheiten überwunden gewesen wären, und so fühlte sich ein nicht geringer Teil der Bevölkerung nach wie vor ausgebeutet. Hu Ping ist der Meinung, dass der Kampf gegen die Intellektuellen eine Möglichkeit dargestellt habe, sich gegen vermeintliche Ausbeuter zur Wehr zu setzen: „Daher ist jede Bewegung eine Flut primitiver Wünsche.“503

Auch hier bezieht er sich wieder auf die persönlichen Erinnerungen von Zeitzeugen. So gibt Wei Xuezhan 卫雪珍, im Jahr 1957 Arbeiterin in einer Zigarettenfabrik, zu Protokoll, dass sie sich damals auf einer Arbeiterkonferenz in Shanghai lautstark darüber beschwert habe, dass in ihrer Fabrik der Lohn für die einfachen Arbeiter monatlich zwischen 56 und 93 Yuan gelegen habe und das bei einem monatlichen Produktionswert von 5.500 bis 8.977 Yuan. Ihre Vorgesetzte hingegen, eine ausgebildete Ingenieurin und damit Intellektuelle, die ebenfalls auf der Konferenz anwesend war, habe einen Monatslohn von 462 Yuan erhalten. $\mathrm{Hu}$ legt mit diesem Fallbeispiel dar, dass während der 1950er Jahre Ungleichheit bzw. Ungerechtigkeit in den Köpfen der Menschen häufig mit Wissen gleichgesetzt worden sei:

Weil Wissen oft als Ketzerei angesehen wurde und dieses Wissen in Geld umgewandelt wurde und dies oft höher war, als die Einkommen der einfachen Arbeiter und Bauern, deswegen war es nur natürlich, dass das Feuer des politischen Hasses das trockene Holz niederbrennen ließ, welches durch Geld unterdrückt worden war. ${ }^{504}$

Sowohl das Aufkeimen des Populismus durch Teile der chinesischen Führungsriege als auch die gezielte Mobilisierung der Massen während der Kampagne gegen Rechtsabweichler haben, so analysiert es $\mathrm{Hu}$, die Grundlagen für den

502 Ebd., S. 425.

503 Eigene Übersetzung. Original siehe ebd., S. 425.

504 Eigene Übersetzung. Original siehe ebd., S. 426. 
Großen Sprung und auch die Kulturrevolution gelegt. Zur Sicherung der Revolution habe man sich fortan immer mehr von rationalen Entscheidungsfindungen gelöst:

Der Große Sprung geht eindeutig mit einem Aufstieg des Populismus einher. Auf wirtschaftlicher Ebene wurden wissenschaftliche und rationale Entscheidungsprozesse mit der großen Begeisterung und Initiative der sogenannten Massen ersetzt. Auf der politischen Ebene bedeutete dies, dass es Mao mit dem Jahr 1957 aufgab, das Wissen, die Sachkenntnis und die Begeisterung der Intellektuellen der nationalen Industrialisierungspolitik dienen zu lassen. Wahrscheinlich war er der Meinung, dass die weitere Umsetzung dieser Politik ein großes Risiko birgt, die Führung der Partei und die Interessen der Partei zu schädigen; stattdessen verließ er sich auf die Begeisterung und Kreativität der Massen mit geringer Professionalität, um die Reinheit und die anhaltende Dynamik der chinesischen Revolution sicherzustellen..$^{505}$

Im Gegensatz zu den in Kapitel 4 diskutierten Werken der offiziellen Geschichtsschreibung findet das Schicksal der Rechtsabweichler innerhalb des Laogai-Systems in $\mathrm{Hu}$ Pings Buch durchaus Erwähnung, wenn auch nicht so ausführlich wie in den wenige Monate zuvor erschienenen Erzählungen Yang Xianhuis. Dabei merkt er zunächst an, dass in den meisten Fällen der Zufall über das Schicksal der Intellektuellen und über ihr Leben in den kommenden 20 Jahren bestimmt habe und nicht etwa unbedingt ihre inkorrekte politische Haltung. Und so kämpften nicht selten eigentlich linientreue Kommunisten nach ihrer Verurteilung erbittert darum, ihren Status als Rechtsabweichler wieder loszuwerden, indem sie beispielsweise keine Gelegenheit ausließen, ihren Glauben an Mao und die Partei zum Ausdruck zu bringen.

Erneut nimmt Hu Bezug auf die Erinnerungen Ge Peiqis, der ihm nur einen Monat vor seinem Tod von seiner Zeit in einem Arbeitslager in Shanxi berichtet hatte, in dem er durch Arbeit umerzogen werden sollte. Auch Ge, der einige Jahre zuvor bereits in Gefangenschaft der Guomindang gewesen war, habe demnach zunächst die größten Anstrengungen unternommen, um zu beweisen, dass er ein Kommunist sowie ein Treuer Anhänger Maos und nicht etwa ein Klassenfeind sei:

In einem GMD-Gefängnis zu sitzen bedeutete, im Gefängnis des Feindes zu sitzen; das Gefängnis des Feindes zu zerstören, war eine der Aufgaben eines Revolutionärs: Aber ein kommunistisches Gefängnis zu zerstören, hätte bedeutet, die sozialistische Ordnung zu untergraben. Selbst wenn ein Mitglied der Kommunistischen Partei wegen Verleumdung inhaftiert wurde, musste man eine Haltung einnehmen, die der Gefängnisordnung entspricht. Für einen Kommunisten bedeutete dies, dass er sich sowohl im Gefängnis des Feindes, als auch in einem kommunistischen Gefängnis bewähren musste. Ich verschaffte

505 Eigene Übersetzung. Original siehe ebd., S. 533.. 
mir einen Vorsprung, indem ich mich diszipliniert verhielt und auf die Einhaltung der Regeln achtete, die Produktionsziele in jedem Monat übererfüllte und die Initiative ergriff, den Inhaftierten dabei zu helfen, Maos Ausgewählte Werke sowie die Kultur zu erlernen und ihre Lernerfahrungen schriftlich festzuhalten und Briefe an ihre Familien zu schreiben. Ich bestand darauf, jeden Tag revolutionäre Literatur zu studieren, las intensiv die vier Bände von Maos Ausgewählten Werken und konnte dutzende Werke, Zitate und Gedichte Maos rezitieren, wie Über die richtige Behandlung der Widersprüche im Volk, Über die Praxis, Über die demokratische Diktatur des Volkes und Die Rede bei der Aussprache in Yan'an über Kunst und Literatur. Ich las auch die Klassiker Marx' und Engels'. ${ }^{506}$

Obwohl Ge Peiqi eigentlich gar nicht umerzogen werden musste, musste er aufgrund seines Status' dennoch eine erfolgreiche Umerziehung und eine korrekte ideologische Haltung demonstrieren. Die Bereitschaft, körperlich hart zu arbeiten, war ebenso Bestandteil einer „erfolgreichen“ Umerziehung. Die Erinnerungen Ge Peiqis, die durch Hu Ping wiedergegeben werden, geben ein Bild davon ab, wie hart die körperliche Arbeit, die die Insassen des Laogai-Systems in jenen Jahren verrichten mussten, tatsächlich sein konnte:

Bei der Arbeit war es so, dass man nicht 100 Pfund Kieselsteine auf den Berghang tragen musste, um die Häuserrinnen zu füllen, sondern man musste Wasser in die Berge bringen, um die Obstbäume zu wässern. Auch wenn man sich auf den kurvenreichen Straßen frei bewegen konnte, keuchten die Kulturschaffenden; diese Art des Arbeitslebens war eher so, als würde ihnen das Rückgrat brechen und als würden ihre Sehnen entfernt werden, einer nach dem anderen taumelte und schwitzte. In der Nacht konnte man seinen verschwitzten Körper nur noch ins kalte Bett legen, man konnte keine Energie und Zeit mehr dafür aufbringen, die Kleidung zu wechseln oder zu waschen, denn es war eine Selbstverständlichkeit geworden, bis tief in die Nacht hinein zu arbeiten. ${ }^{507}$

Die Schrecken der Arbeitslager und die darin erlittenen Schicksale der Rechtsabweichler werden durch $\mathrm{Hu}$ jedoch nicht so intensiv und deutlich dargestellt, wie in einigen Memoiren von Zeitzeugen respektive Dissidenten. Beispielweise wird das Thema des Hungers der Insassen nur am Rande erwähnt. Weitgehend unerwähnt bleibt beispielsweise auch die Willkür von Wärtern, die Insassen teilweise sogar zu Tode prügelten. Ebenso verzichtet Hu Ping auf eine Verknüpfung zur Gegenwart, das heißt, die Existenz von Arbeitslagern im China der Entstehungszeit des Buches bleibt unerwähnt. ${ }^{508}$ Möglicherweise hat Hu Ping auf

506 Eigene Übersetzung. Original siehe ebd., S. 519.

507 Eigene Übersetzung. Original siehe ebd., S. 520.

508 Eine deutlichere Darstellung des Schreckens lässt sich beispielsweise in den Memoiren Harry Wus wiederfinden, ebenso wie ein Bericht über Arbeitslager im post-maoistischen China. Siehe Wu und Vecsey 1996. 
eine dezidiertere Darstellung des Schreckens des Laogai-Systems deshalb verzichtet, um eine Zensur durch die chinesischen Behörden zu vermeiden.

Insgesamt wechseln sich Hu Pings metaphorische Darstellungen der Ereignisse rund um die Kampagne gegen Rechtsabweichler und den damit verbundenen Ausbruch des Populismus in den von ihm eingesetzten sprachlichen Mitteln auch immer wieder mit sehr deutlichen kritischen Äußerungen ab. Beispielsweise zieht er einen sehr drastischen Vergleich mit den Konzentrationslagern, als er noch einmal kritisch bilanziert, welche Bedeutung die Jahre 1957 und 1958 für die Intellektuellen in China hatten, durch die die Intellektuellen hinter eine Mauer des Schweigens geraten seien:

Wenn man sagt, dass das Jahr 1957 die Guillotine der Rechtsabweichlerpolitik war und im Jahr 1958 das Damoklesschwert über den Köpfen der Intellektuellen schwebte, welches unvermeidlicherweise jederzeit fallen konnte; wenn man sagt, dass im Jahr 1957 viele Rechtsabweichler zum Mond flogen, um die Sterne zu verdecken und um dann in den kargen Landschaften in Arbeitslagern zu arbeiten. Im Jahr 1958 wurden schließlich alle Intellektuellen in große, unsichtbare Konzentrationslager gebracht und natürlich war es nicht die Polizei oder die Armee, die diese bewachten, sondern die strikte Armee des Populismus. ${ }^{509}$

Der letzte Teil des Buches beschäftigt sich mit der Phase nach dem Tode Maos, den politischen Umbrüchen und dem in jenen Jahren erfolgten Umgang mit den Intellektuellen, die der Kampagne gegen Rechtsabweichler zum Opfer gefallen sind.

Zunächst äußert er sich kritisch zu dem unreflektierten Umgang Hua Guofengs mit Mao Zedong, der durch das sture Festhalten an der Ikone keinen Neuanfang anzustoßen vermochte:

\begin{abstract}
Dies widersprach der ursprünglichen Intention des Entscheidungsträgers Hua Guofeng, ${ }^{510} \mathrm{er}$ wollte seine Position nur konsolidieren und diese nicht ins Wanken bringen. Somit konnte er nur eine Ära erben und keine neue Ära kreieren. Er baute ein Gebäude auf Fehlern, veröffentlichte den fünften Band der Ausgewählten Werke Mao Zedongs und begann sogleich mit der Auswahl des Standorts der Mao-Zedong-Gedenkstätte ... Er stellte Eis am Rande des Magmas her und dann arbeiteten Wang Dongxing, ${ }^{511} \mathrm{Wu} \mathrm{De}^{512}$ und andere hart daran, Eis in die Fehler zu werfen. ${ }^{513}$
\end{abstract}

509 Eigene Übersetzung. Original siehe Hu 2004, S. 534.

510 Gemeint ist hier die Verhaftung der Viererbande am 06. Oktober 1976.

511 Wang Dongxin 汪东兴 war zwischen August und Oktober 1977 einer der Stellvertretenden Vorsitzenden der KPCh und wurde von Hu Yaobang abgelöst.

$512 \mathrm{Wu}$ De 吴德 war einer der wichtigsten Unterstützer Hua Guofengs und von 1973 bis 1980 Mitglied des Politbüros der KPCh, bevor er von Deng Xiaoping aus der Politik gedrängt wurde. 513 Eigene Übersetzung. Original siehe ebd., S. 633. 
Deng Xiaoping, der bezüglich des Umgangs mit dem historischen Erbe Maos zwar eine andere Haltung angenommen hatte als Hua Guofeng, habe sich aufgrund der Machtkämpfe, so analysiert es $\mathrm{Hu}$, in der Phase direkt nach Maos Tod in einer äußerst schwierigen Lage befunden:

Sicherlich hat er die Brüche Chinas gesehen, das sich auf einer Irrfahrt zwischen Selbstaufgabe und Entscheidungsfreiheit sowie zwischen Demontage und Neuaufbau befand. Weil er nichts aufgeben konnte, konnte er auch keine Wahl treffen und agierte ängstlich; weil er nichts einreißen konnte, konnte er auch nichts wiederaufbauen und war voller Unzufriedenheit. ${ }^{514}$

Hu Ping nimmt gegenüber dem eigentlichen Hauptverantwortlichen der Kampagne, wie in den vorherigen Kapiteln auch, auf den ersten Blick eine recht unkritische Haltung ein. Vielmehr betont er zunächst, dass Deng spätestens ab Mai 1977 dem Wissen und damit auch den Intellektuellen wieder einen höheren Stellenwert habe zukommen lassen. Hier führt er einige direkte Zitate Dengs an, die er diversen historischen Quellen entnommen hat. Beispielsweise soll er in einem Gespräch mit seinen damaligen politischen Verbündeten Wang Zhen 王震 und Deng Liqun 邓力群 ${ }^{515}$ gesagt haben: „Es ist notwendig, innerhalb der Partei eine Atmosphäre zu schaffen, Wissen $\mathrm{zu}$ respektieren und Talente $\mathrm{zu}$ respektieren. Unabhängig von geistiger Arbeit oder körperlicher Arbeit ist es Arbeit, und es ist notwendig, auf Arbeiter zu achten, die geistige Arbeit verrichten.“"516

Den zentralen Stellenwert für die politischen und gesellschaftlichen Umbrüche, insbesondere im Umgang mit den Intellektuellen, schreibt $\mathrm{Hu}$ Ping jedoch nicht Deng Xiaoping, sondern Hu Yaobang zu. Demnach habe Hu Yaobang nicht nur den politischen Anstoß für die „Rehabilitierungen“ der Rechtsabweichler gegeben, sondern habe durch sein politisches Wirken auch die Grundlagen für Deng Xiaopings Reformen gelegt:

Hu Yaobang hat beinahe eine neue Ära der Befreiung der Menschen eingeleitet. Er hat das Schicksal der Menschen majestätisch in seine eigenen Hände gelegt und damit die Grundvoraussetzungen für Deng Xiaoping geschaffen, ein China voller Brüche auf den Pfad der Regeneration zu führen. Was von noch größerer Besonderheit zeugt, ist die Tatsache, dass sich Hu Yaobangs herausragende Leistung auch in seiner korrekten Haltung den Intellektuellen gegenüber widerspiegelte. ${ }^{517}$

514 Eigene Übersetzung. Original siehe ebd., S. 634.

515 Beide nahmen rund zehn Jahre später eine kritische Haltung gegenüber der Reform- und Öffnungspolitik Dengs ein. Siehe Ruan und Liu 1994, S. $120 \mathrm{ff}$.

516 Eigene Übersetzung. Original siehe Hu 2004, S. 635.

517 Eigene Übersetzung. Original siehe ebd., S. 637. 
Durch diese Darstellung übt er, wenn auch nur zwischen den Zeilen, durchaus Kritik an Deng, dem er keine zentrale Rolle im Zuge der „Entfernung der Hüte“ der Rechtsabweichler ab dem Jahr 1978 zuspricht.

Wie bereits in Kapitel 3 ausgeführt, spielt die Umsetzung der „Rehabilitierungen“ der Rechtsabweichler in der inoffiziellen Geschichtsschreibung insbesondere durch Zeitzeugen und ihre Angehörigen eine große Rolle, was, wie auch $\mathrm{Hu}$ Ping kritisch betont, der Tatsache geschuldet sei, dass ihnen, im Gegensatz zu vielen anderen politischen Opfern, formal keine Rehabilitation, sondern nur eine Korrektur ihres falschen Status zugekommen sei. Kritisiert wird dabei häufig, dass diejenigen, deren Urteile nur korrigiert worden waren, nicht die gleiche finanzielle Kompensation zugesprochen bekamen, wie diejenigen, die vollständig rehabilitiert worden sind.

Hu Ping verweist hier auf das am 17. September 1978 verabschiedete Dokument Nr. 55, welches die „Entfernung der Hüte“ einläutete und die formale Umsetzung der Einzelfallkorrektur der Rechtsabweichler regelte. ${ }^{518}$ Auch wenn er ob der Ungleichbehandlung der Rechtsabweichler, die eben nicht rehabilitiert worden sind, in seinen Ausführungen eine sehr kritische Haltung einnimmt, betont er dennoch, dass dieses Dokument den Rechtsabweichlern ermöglicht habe, „sich von Geistern in Menschen zu verwandeln“. ${ }^{519}$

Auch wenn er Hu Yaobang eine Schlüsselrolle im Umgang mit den Intellektuellen zuschreibt und Deng Xiaoping zwischen den Zeilen einer kritischen Betrachtung unterwirft, relativiert er dies dennoch wieder, indem er betont, dass $\mathrm{Hu}$ Yaobang und Deng Xiaoping in dieser Phase eng zusammengearbeitet hätten und sich das Volk der Partei gegenüber ebenfalls solidarisch gezeigt habe. ${ }^{520}$

Im Nachwort wird erneut deutlich, dass Veröffentlichungen wie diese auch alternative Erinnerungsorte darstellen können. Denn Hu Ping unterstreicht hier noch einmal, dass das Schicksal seines eigenen Vaters und dessen Sprechen über seine Erinnerungen an die Erlebnisse ab dem Jahr 1958 den entscheidenden Impuls für das Schreiben des Buches geliefert haben. Auch wenn der Vater nach seiner Entlassung wieder an seinen alten Posten an der Universität zurückkehren konnte, habe er Zeit seines Lebens nicht überwinden können, dass er von der Partei einst so beseitigt worden war. Hiermit macht Hu Ping auch nochmal deutlich, dass die Opfer der Kampagne noch viel länger mit den Folgen zu kämpfen hatten, als nur bis zu ihrer Entlassung aus dem Laogai-System, vielmehr würde das Erlebte die Unschuldigen bis zu ihrem Tode verfolgen. Und so betont er

518 Siehe Kapitel 3.

519 Eigene Übersetzung. Original siehe ebd., S. 641.

520 Ebd., S. 650. 
am Schluss, dass das Schicksal seines Vaters stellvertretend für das Schicksal vieler stehe und dieses kollektive Schicksal in diesem Buch beschrieben werden sollte.

Insgesamt erzählt $\mathrm{Hu}$ Ping die Geschichte der Kampagne gegen Rechtsabweichler anhand verschiedener individueller Einzelschicksale. Dabei nimmt das individuelle Gedächtnis einen wichtigen Stellenwert ein, da er sich in seinen Ausführungen häufig auf von ihm selbst geführte narrative Interviews bezieht. Dennoch kann das Buch als vielschichtiges Werk beschrieben werde, da es sich auch auf historische Dokumente bezieht, welche auch häufig durch analytische Abschnitte ergänzt werden. Diese Vielschichtigkeit spiegelt sich auch in der Sprache wider, die abwechselt zwischen einem metaphorischen und blumigen Stil einerseits und klaren und prägnanten Sätzen bzw. Abschnitten andererseits.

Trotz der stellenweise sehr klaren Darstellungen der „historischen Fehler“ der KPCh und des Äußerns von Kritik, konnte das Buch (zunächst) in der VR China veröffentlicht werden. Ein Grund hierfür kann in der metaphorischen Sprache zu finden sein, die die Kritik etwas milder erscheinen lässt. Insbesondere jedoch dürfte die Tatsache ausschlaggebend gewesen sein, dass $\mathrm{Hu}$ Ping, trotz seiner eindeutig kritischen Haltung, die Herrschaftslegitimation der KPCh in diesem Buch nicht explizit herausfordert und im Wesentlichen noch innerhalb der Grenzen des Sagbaren, das heißt im von der KPCh noch tolerierten Bereich, agiert, auch wenn seine Darstellungen deutlich über die Narrative der offiziellen Geschichtsschreibung hinausgehen respektive diese herausfordern. Dementsprechend ruft er in seinem Schlusswort dazu auf, die Vergangenheit gesellschaftlich $\mathrm{zu}$ reflektieren, um $\mathrm{zu}$ einer besseren Zukunft zu gelangen.

Ich denke, es gibt auf der Welt immer Menschen, die das Schwierige durchdringen müssen; nur wenn wir die Schwierigkeiten und Wirrungen, die wir erlebt haben, sorgfältig deuten, können wir auf dem heutigen Feuerstein zu einem gemeinsamen Glauben an das Leben und das Arbeiten gelangen, das würde bedeuten, dass die Zivilisation unbesiegbar ist und die Wissenschaft ewig währt; heute ist besser als gestern und morgen ist besser als heute. ${ }^{221}$

Insgesamt lässt sich Hu Pings Werk als wichtigen Beitrag zur Neudeutung der Geschichte der Kampagne gegen Rechtsabweichler werten, welches dadurch auch einen wichtigen Einfluss auf das kollektive Gedächtnis ausübt. ${ }^{522}$

521 Eigene Übersetzung. Original siehe ebd., S. 728.

522 Vgl. Leutner 2007, S. 81. 